\title{
ANÁLISIS PROSÓDICO DE LAS ESTRUCTURAS TRUNCADAS EN LA CONVERSACIÓN COLOQUIAL ESPAÑOLA: FUNCIONES DE FORMULACIÓN Y ATENUACIÓN ${ }^{1}$
}

\section{A PROSODIC ANALYSIS OF TRUNCATED STRUCTURES IN SPANISH COLLOQUIAL CONVERSATION: THE FUNCTIONS OF FORMULATION AND MITIGATION}

\author{
Elena Pascual Aliaga \\ Universitat de València \\ Grupo Val.Es.Co. \\ Elena.Pascual@uv.es
}

Recibido: 02/02/2017

Aceptado: 03/08/2017

\section{Resumen}

Este trabajo analiza las características prosódicas de las estructuras truncadas en la conversación coloquial española con el fin de determinar si los rasgos prosódicos son índices predictivos de las funciones de formulación y atenuación. A partir de un estudio de corpus de conversaciones espontáneas, se analizan determinados fenómenos -duración, velocidad de habla, F0, pausas, inflexiones tonales- para elucidar si existe una correlación entre la interfaz prosódica y la pragmática.

PALABRAS CLAVE: estructura truncada, prosodia, atenuación, formulación, conversación coloquial.

\begin{abstract}
This study analyses the prosodic features of truncated structures in Spanish colloquial conversation with the aim of determining whether these prosodic features are predictable indices of the pragmatic functions of formulation and mitigation. By carrying out a corpus-based study of spontaneous conversations, some prosodic features -duration, speech rate, F0, pauses, tone inflexions- are analysed in order to elucidate whether there is a correlation between the prosodic and pragmatic interface.

KEY WORDS: truncated segment, prosody, mitigation, formulation, colloquial conversation.
\end{abstract}

1 Esta investigación ha contado con la ayuda del proyecto de I+D Unidades discursivas para una descripción sistemática de los marcadores del discurso en español (UDEMADIS, ref. FFI2016-77841-P) del Ministerio de Economía, Industria y Competitividad (MINECO) y del Fondo Europeo de Desarrollo Regional (FEDER); así mismo, esta investigación ha sido posible gracias a la Ayuda para la formación de doctores del programa nacional de formación de profesorado universitario (ref. FPU14/06378) del Ministerio de Educación, Cultura y Deporte, de la cual la autora es beneficiaria.

Para citar este artículo / To cite this article: Pascual Aliaga, Elena (2018): Anñalisis prosódico de las estructuras truncadas en la conversación coloquial española: funciones de formulación y atenuación. García Ramón, Amparo y Soler Bonafont, María Amparo (Eds.): ELUA: Estudios de atenuación en el discurso, Anexo IV, págs. 57-84.

Enlace / Link: http://dx.doi.org/10.14198/ELUA2018.Anexo4.04 


\section{INTRODUCCIÓN}

La espontaneidad es una de las características más distintivas del habla coloquial (Beinhauer 1978; $c f$. Narbona 1992: 727): la inmediatez de la situación comunicativa, la planificación del discurso sobre la marcha, el dinamismo o la alternancia de turnos no predeterminada son rasgos de la conversación coloquial (Briz 1998: 40-43) que propician la aparición de fenómenos sintácticos particulares como vacilaciones, reinicios, repeticiones, truncamientos y pausas llenas, esto es, elementos truncos que marcan los procesos de planificación y construcción del discurso. Si bien este tipo de segmentos puede vincularse con estrategias de formulación o de modalización (Briz 2017), estas estructuras no han sido apenas contempladas como objeto de estudio de la sintaxis coloquial en español (Pose 2011: 13), tampoco desde una perspectiva pragmática, como son los estudios sobre atenuación (donde sí se menciona, sin embargo, que las estructuras truncadas pueden ser un procedimiento atenuador (Albelda, Briz, Cestero, Kotwica y Villalba 2014)), ni mucho menos desde una perspectiva prosódica. El presente estudio es una primera aproximación que trata de cubrir este vacío teórico.

Esta investigación toma como base algunos trabajos sobre estructuras tales como los actos suspendidos, truncados y los reinicios (Pérez 2011, 2014, 2015), en los que se apunta hacia una posible interrelación entre los rasgos prosódicos de las estructuras incompletas y la función discursiva que desempeñan. En las construcciones suspendidas se ha demostrado que la prosodia (valores de F0, presencia de alargamientos) puede ayudar a discernir estrategias de atenuación o intensificación (Pérez 2015: 231-232). A su vez, suele aducirse que la prosodia es un índice fundamental para el reconocimiento de la atenuación (para su correcta interpretación se recomienda apoyarse en la señal auditiva (Briz y Albelda 2013: 306)), pero más allá de esta afirmación impresionista, escasean los estudios dedicados a la relación entre prosodia y atenuación, siendo algunas excepciones trabajos como los de Devís (2011a) o Hidalgo (2006, 2009), entre otros ${ }^{2}$.

El objetivo principal de este trabajo es describir los rasgos prosódicos de las estructuras truncadas de la conversación coloquial española -duración, velocidad de habla, altura tonal (F0), presencia de pausas, alargamientos e inflexiones tonales a final de sílaba- con el fin de ver si están directamente relacionados con las funciones de formulación y modalización. Partimos de la hipótesis de que hay una correspondencia entre la estructura formal (prosódica) y las funciones pragmáticas, y la pregunta principal que se pretende responder es: ¿hasta qué punto la prosodia es un índice predictivo de la función de las estructuras truncadas?

\section{LAS ESTRUCTURAS TRUNCADAS: DEFINICIÓN, FORMA Y FUNCIONES}

\subsection{Definición}

Según describe Shriberg (1994: 7-30) en uno de los principales trabajos monográficos que existen sobre las denominadas disfluencias, no hay una teoría integral que defina y clasifique los fenómenos implicados en la interrupción de la fluencia del habla (vacilaciones, pausas llenas, repeticiones, autocorrecciones, etc.). En el ámbito de la lingüística española,

2 Devís (2011a: 38) cita los siguientes estudios sobre atenuación desde una perspectiva entonativa: Quilis (1988; 1993), Haverkate (1994), Hidalgo (2001; 2006; 2007; 2009), Álvarez y Blondet (2003), Waltereit (2005), Briz e Hidalgo (2008) y Devís (2011b). 
estos fenómenos han sido poco estudiados ${ }^{3}$, lo cual no deja de ser sorprendente, dado que la creciente reivindicación del estudio de lo coloquial (Narbona 1992, Briz 1998) invita a tomar en consideración tales fenómenos, tan frecuentes y propios de la lengua hablada. La definición de las estructuras truncadas de la que partimos se articula en base a dos criterios: uno formal, referido a la incompletud estructural del segmento (§ 2.1.1.); y uno pragmático, relativo a su función general en la interacción (§ 2.1.2.). Esta definición no distingue, a prio$r i$, ningún tipo de fenómeno concreto o ningún subtipo de función o estrategia discursiva.

\subsubsection{Segmentos estructuralmente incompletos}

Optamos por emplear el término estructura trunca o truncada, en lugar de disfluencia u otros, porque tiene un carácter neutro y genérico que da cuenta de la incompletud estructural de un segmento ${ }^{4}$. Los truncamientos son elementos cuya enunciación se interrumpe, como en $(1)^{5}$ :

(1) E: ¿la de la derecha o de la- ee recto?

Para que se produzca una estructura trunca debe haber necesariamente a) una interrupción prosódica del flujo del habla, la cual, a su vez, produce b) un segmento sintácticamente -y a veces también morfológicamente- incompleto.

a. La interrupción del habla se lleva a cabo mediante marcas (pausas silenciosas, pausas llenas -ee, $\mathrm{mm}$-, alargamientos vocálicos o inflexiones tonales marcadas) que delimitan un grupo de entonación ${ }^{6}$ cuyo contenido queda inacabado, esto es, lo que Chafe (1993: 37-38) denomina una unidad entonativa fragmentaria.

3 Pueden destacarse, no obstante, trabajos sobre fenómenos como los anacolutos (Bedmar 1987; Bedmar y Pose 2007; 2008), las construcciones suspendidas (Pérez 2011; 2014; 2015, entre otros), los actos truncados (Pose 2011) o la propuesta de Briz (2017) sobre los cortes sintácticos. Merece especial mención la única clasificación existente en lengua española -al menos desde el conocimiento de la autora de este trabajo- sobre las denominadas construcciones fragmentadas, realizada por Herrero (1995).

4 Términos como auto-corrección o reinicio, por ejemplo, parecen remitir a funciones o características sintácticas concretas como la corrección o a la introducción de un nuevo enunciado. No adoptamos la denominación truncada empleada en otros trabajos (Pose 2011; Pérez 2011; 2014; 2015) en los que se distingue construcciones suspendidas, truncadas y reinicios, según sean estructuras emitidas intencionalmente (suspendidas y truncadas) o no (reinicios) por el hablante. Si bien las estructuras suspendidas no forman parte de nuestro objeto de estudio (vid. §2.1.2), sí pretendemos abarcar tanto las construcciones truncadas como los reinicios, sin distinguir de antemano una función preconcebida en su emisión. No adoptamos tampoco la terminología establecida por Herrero (1995), ya que nuestro objeto de estudio incluye lo que esta autora denomina construcciones fragmentadas y enunciados recodificados, entre otros tipos de estructuras. Desde nuestra perspectiva, el término estructura truncada permite reagrupar intuitivamente distintos fenómenos sin especificar sus rasgos estructurales - mas allá de su incompletud-y sus funciones.

5 Los ejemplos están extraídos del Corpus Val.Es.Co. 2.0 (Cabedo y Pons 2013) y siguen las convenciones de transcripción de Briz y grupo Val.Es.Co. (2014: 66-67).

6 Seguimos la definición de grupo entonativo de Quilis et alii (1993: 56-57): "Porción de discurso comprendida entre dos pausas e inflexión del fundamental, entre inflexión del fundamental y pausa, o entre dos inflexiones del fundamental que configura una unidad sintáctica más o menos larga o compleja (sintagma, cláusula, oración)”. Consideramos la pausa como frontera prosódica cuando supera los $200 \mathrm{~ms}$; en cuanto a las inflexiones, aplicamos

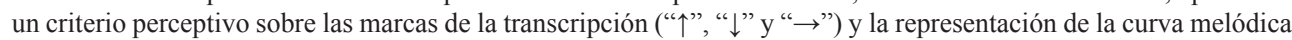
en el programa Praat (Boersma y Weenink 2016), pese a que, tal y como advierte Cabedo (2011: 209), este método presupone una fuerte carga interpretativa por parte del analista. 
b. El contenido del grupo de entonación fragmentario queda incompleto y desgajado sintácticamente del resto de unidades entonativas que se emiten; en ocasiones, el segmento presenta también un truncamiento morfológico, si la interrupción se produce en medio de una palabra.

\subsubsection{Finalidad: lograr una interacción exitosa}

Para establecer la función general de un truncamiento nos basamos en la definición de la estructura self-repair (auto-reparación), estudiada por la corriente del análisis conversacional (Sacks, Schegloff y Jefferson 1974). Una auto-reparación es un mecanismo que lleva a cabo el interlocutor en su turno de habla para resolver (reparar) problemas relacionados con la producción, la recepción o la comprensión del habla en la conversación (Schegloff, Sacks y Jefferson 1977; Schegloff 1979). Este mecanismo supone una interrupción del habla y un movimiento informativo prospectivo o retrospectivo, que puede -aunque no necesariamente- incluir un reemplazamiento o modificación de lo dicho; la auto-reparación no está necesariamente motivada por la presencia de un error o incorrección en el habla, así como tampoco la presencia de un error en lo dicho genera siempre una auto-reparación.

Desde esta perspectiva, quedan fuera de nuestro estudio segmentos como el enunciado por A en (2), esto es, construcciones suspendidas -prosódica y sintácticamente truncasque son unidades comunicativamente plenas, cuyo contenido se recupera inferencialmente (Pérez 2011, 2014, 2015), y que no se vinculan con una función de prevención o resolución de problemas comunicativos:

(2) A: [...] una persona que sabe que juega mal directamente juega de risa o eso no se dedica aa B: noo juegas un poquillo en plan va ((me llega)) la bolaa le doy una y fuera ¿sabes?

En resumen, consideramos que un truncamiento es un segmento estructuralmente incompleto, producido por un hablante en su intervención o turno, que tiene por objeto solventar o prevenir problemas relacionados con la propia producción, la percepción o la comprensión del habla en el curso de la interacción. Esta definición permite abarcar un amplio conjunto de fenómenos y de funciones discursivas.

\subsection{Estructura formal}

\subsubsection{Delimitación interna}

Los movimientos de auto-reparación se producen en tres fases que se suceden cronológicamente en el habla (Levelt 1983: 44-45; Shriberg 1994: 7-9) ${ }^{7}$, con lo que su estructura se compone de tres partes (Figura 1):

7 Adoptamos la propuesta de Shriberg (1994: 7-9) para las nociones de reparandum y de interregno (cf. editing phase (Levelt 1983)). 


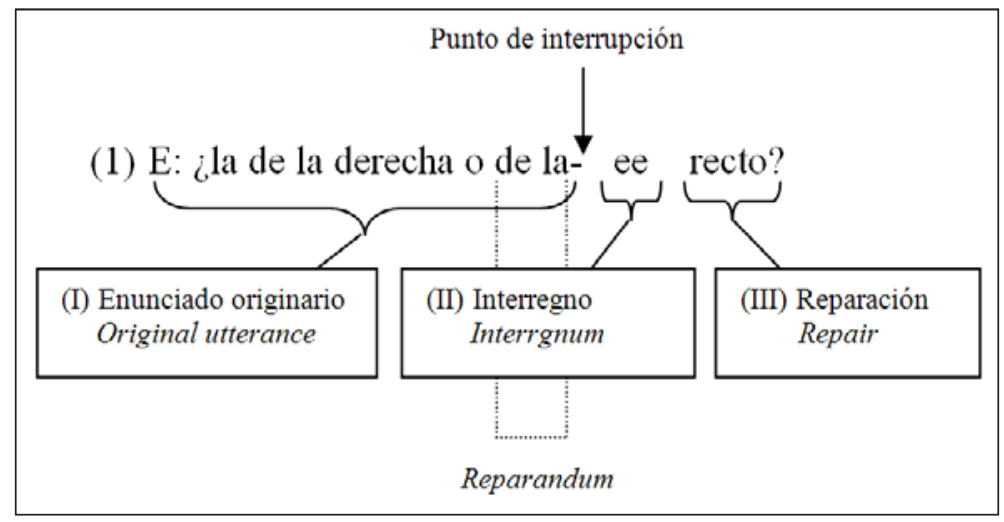

Figura 1. Las partes de una estructura truncada.

I. En primer lugar, el hablante interrumpe el enunciado que está pronunciando (enunciado originario) en un momento determinado (punto de interrupción), dando lugar a una secuencia trunca. Una parte o la totalidad del enunciado original puede contener elementos lingüísticos (el reparandum) que se modifican o que directamente se abandonan más adelante cuando se retoma la enunciación; es el caso de la secuencia de la- en la Figura 1, que es un contenido sustituible por el segmento reparador "recto".

II. En segundo lugar, puede producirse facultativamente un momento de hesitación (interregno) en el que suelen aparecer pausas llenas, marcas de vacilación, partículas de reformulación o enunciados como quiero decir, entre otros elementos ${ }^{8}$. Es un espacio que se sitúa entre el enunciado originario y la reparación.

III. Por último, el hablante retoma el curso del habla (reparación), bien de forma retrospectiva, volviendo sobre el enunciado originario, o bien de forma prospectiva, prosiguiendo con otro enunciado distinto que puede guardar relación (ampliar, sustituir, eliminar, reformular) o no con el enunciado original y el reparandum.

Este trabajo incluye únicamente las estructuras truncadas compuestas por las tres partes, esto es, por un enunciado original (EO) interrumpido, un interregno (I) que incluye explícitamente uno o varios elementos lingüísticos y una reparación $(\mathrm{R})^{9}$. Quedan excluidos los truncamientos que solo presentan material lingüístico en una o dos de las partes mencionadas, como sucede en los siguientes ejemplos ${ }^{10}$, en los que o bien no hay EO y la intervención comienza en el momento de hesitación, como sucede con la pausa llena (ee) y la vacilación $(j-)$ en (3); o bien el habla se trunca y se prosigue sin que aparezca un I, como en la repetición de vacilación (4); o bien no se llega a enunciar la $\mathrm{R}$ por motivos como, por ejemplo, un robo de turno, como sucede en (5) tras eem:

8 Consideramos también los incisos como elementos del interregno.

9 De aquí en adelante, se utilizarán las siglas EO, I y R.

10 Con el fin de distinguir las tres partes de la estructura en los ejemplos, el elemento del interregno aparecerá subrayado. 
(3) E: ¿una cena de cuántos?

ED: ee j-/ ((no los he contao)) seremos a lo mejor ocho o diez

(4) C: [Vane] se queja mucho $\S$

D: $\quad \S$ y encima ahora que [estáa- está ingresada]

(5) A: [...] la excusa de Cristian es la más chunga por ahora ¿eh? porque yoo hacer el Camino de Santiago lo veo// irse de campamento también// [eem] B:

[yy] si los exámenes [normales los tienes] que hacer $[\ldots]$

Puede suceder que se produzcan dos o más estructuras truncas seguidas. En estos casos, se reconoce cada estructura individualmente. En (6), yo lo que decía es que es a la vez $\mathrm{R}$ del enunciado yoo y EO ante el interregno a ver si me entiendes joder:

(6) B: \# yoo o sea yo lo que decía es que- a ver si me entiendes joder/ yo/ un- una pareja// folla y se queda preñada $\uparrow$ se jode/ que tome $\uparrow$ medidas

Si bien es posible delimitar la estructura interna de los truncamientos, delimitar sus fronteras externas -identificar dónde comienza el EO y dónde termina la $\mathrm{R}$ - podría resultar más problemático. Identificar unidades de análisis se hace, en este sentido, necesario tanto para delimitar la propia estructura del resto de elementos de la intervención de un hablante, como para fijar mejor los límites internos de la estructura y estudiar, así, sus propiedades acústicas a partir de las unidades que la conforman. Dado que las unidades de la sintaxis oracional no permiten analizar las estructuras truncas, ya que las relegan al ámbito de la marginalidad sintáctica o la agramaticalidad, optamos por emplear el sistema de unidades que propone el grupo Val.Es.Co. (Briz y Grupo Val.Es.Co. 2003, 2014) ${ }^{11}$, el cual se adapta mejor a las necesidades del objeto de estudio.

\subsubsection{Delimitación a partir del modelo Val.Es.Co.}

El sistema de unidades conversacionales del grupo Val.Es.Co. (Briz y Grupo Val.Es.Co. 2003, 2014) presenta un total de ocho unidades, las cuales están interrelacionadas con dos niveles (monológico y dialógico) y tres dimensiones (estructural, social e informativa), como muestra la Tabla 1:

\begin{tabular}{|l|l|l|l|}
\hline \multirow{2}{*}{ NIVEL } & \multicolumn{3}{|c|}{ DIMENSIONES } \\
\cline { 2 - 4 } & \multicolumn{1}{|c|}{ ESTRUCTURAL } & \multicolumn{1}{c|}{ SOCIAL } & INFORMATIVA \\
\hline \multirow{2}{*}{ Dialógico } & $\begin{array}{l}\text { discurso } \\
\text { diálogo } \\
\text { intercambio }\end{array}$ & alternancia de turno & \\
\hline Monológico & $\begin{array}{l}\text { intervención } \\
\text { acto }\end{array}$ & turno & subacto \\
\hline
\end{tabular}

Tabla 1. Niveles, dimensiones y unidades del sistema Val.Es.Co.

(Briz y Grupo Val.Es.Co. (2014: 14))

11 Valencia Español Coloquial. 
Las unidades más importantes para el análisis de las estructuras truncadas son las inferiores a la intervención: el acto y el subacto. También son relevantes los denominados segmentos subestructurales (Pascual en preparación) que no llegan a constituir unidad.

El acto es un segmento aislable, inferior a la intervención, que posee fuerza ilocutiva; representa una acción-intención y sus fronteras son identificables mediante determinadas marcas lingüísticas -curva melódica completa, presencia de marcadores discursivos, etc.(Briz y Grupo Val.Es.Co. 2014: 37-51). Siguiendo la propuesta de Pons (2016: 552-556), el acto puede identificarse con base en tres criterios: prosódico -coincidencia con unidades entonativas-, proposicional -coincidencia con una proposición y sus elementos extraproposicionales- e ilocutivo - presencia de fuerza ilocutiva-.

El subacto es el segmento informativo mínimo, el constituyente inmediato del acto, y se identifica mediante dos criterios, el prosódico (a) y el semántico-informativo (b) (Briz y Grupo Val.Es.Co. 2014: 52-61):

a. tiene autonomía fónica y puede constituir un grupo entonativo ${ }^{12}$, aunque, como demuestran algunos trabajos (Hidalgo y Padilla 2006; Cabedo 2009, 2011, 2014; Briz y Grupo Val.Es.Co. 2014; Pascual 2015), no siempre hay una correspondencia unívoca entre subactos y grupos entonativos.

b. puede presentar tres tipos de contenido: proposicional primario (narrativo, descriptivo, argumentativo, factitivo, etc.), es el caso de los subactos sustantivos directores; proposicional secundario (causal, condicional, de finalidad, de tiempo, de lugar, topicalizado, etc), en el caso de los subactos sustantivos subordinados y topicalizados; y extraproposicional (los marcadores del discurso, por ejemplo), que es el propio de los subactos adyacentes.

La Figura 2 muestra los distintos tipos de subacto $^{13}$ :

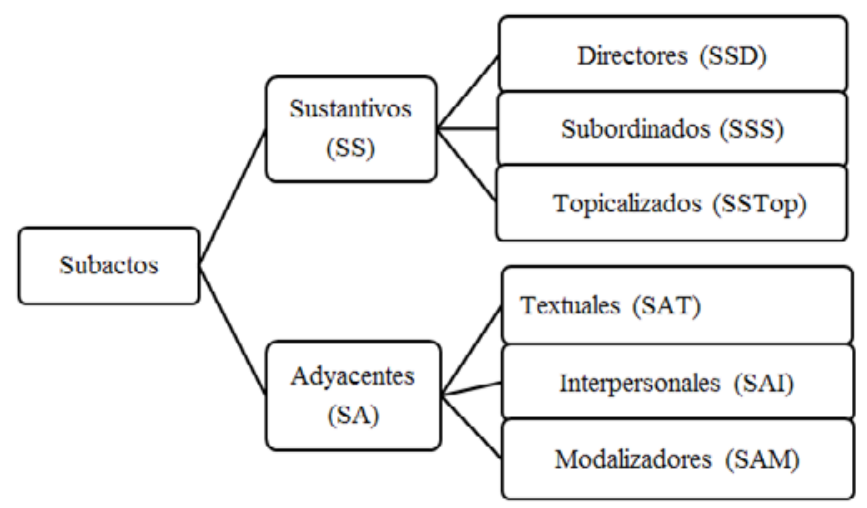

Figura 2. Tipos de subacto.

12 Además de la correspondencia con el grupo entonativo (vid. nota 6), hay otras marcas prosódicas que permiten reconocer tipos de subactos descritas en Hidalgo y Padilla (2006).

13 De ahora en adelante se utilizarán las siglas de la figura 3 para hacer referencia a los tipos de subacto. 
Así mismo, existen segmentos subestructurales que no llegan a conformar unidades con un sentido informativo ni comunicativo completo (Pascual en preparación). Para anotar estos segmentos seguimos la propuesta de Pons (2016), que establece las marcas SSX (subacto sustantivo de naturaleza indeterminada), SAX (subacto adyacente de naturaleza indeterminada) y SXX (subacto de naturaleza indeterminada).

Para delimitar externamente la estructura truncada nos basamos en la unidad acto. Un truncamiento puede estar enmarcado en uno (7) ${ }^{14}$, dos (8) o tres (9) actos. Tanto el EO, el I como la $\mathrm{R}$ pueden pueden corresponderse con un acto, subacto o subestructura:

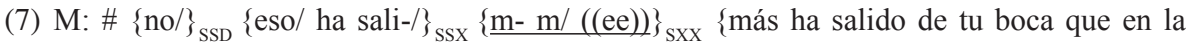
televisión $/\}_{\text {sss }}\{\text { porque yo solamente te lo he visto a ti }\}_{\text {sss }} \#$

(8) B: \# $\{\text { yoo }\}_{\text {SSX }}\{\underline{\text { o sea }}\}_{\text {SAT }}$ yyo lo que decía es que- $\}_{\text {SSD }}\{\underline{\text { a ver si me entiendes }}\}_{\text {SAI }}$ jioder $\left./\right\}$ SAM $\# \#\{\text { yo } /\}_{\text {SSX }}\{\text { un- una pareja// folla y se queda preñada } \uparrow\}_{\text {SSD }}\{\text { se jode } /\}_{\text {Sss }}\{$ que tome $\uparrow$ medidas $\}_{\text {Sss }} \#$

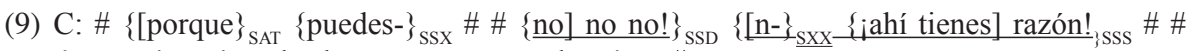
$\{\text { porque }\}_{\mathrm{SAT}}\{\text { puedes hacer unas cosas ahí } \rightarrow\}_{\mathrm{SSD}} \#$

\subsection{Funciones}

Siguiendo la propuesta de Briz (2017), los truncamientos sintácticos, de ser provocados intencionalmente por el hablante, pueden ir ligados a dos funciones comunicativas: la formulativa o la modalizadora; en este último caso, los truncamientos constituyen mecanismos de atenuación o de intensificación. Pese a que los truncamientos también pueden vincularse a una estrategia de realce ${ }^{15}$, los objetivos de este estudio abarcan exclusivamente las funciones de formulación y atenuación.

\subsubsection{Formulación}

Las estrategias de formulación permiten trabar y construir progresivamente el discurso sobre la marcha (funciones textuales de trabazón, de progresión y precisión informativa, de focalización, de topicalización, de robo de turno o de enganche interactivo (Briz 2017)). En (10), B interrumpe la palabra Bena- para precisar informativamente una localización concreta:

(10) B: y luego aquí en Valencia $\uparrow$ hay otra aquí en Jacinto Bena- ¡bueno! al final de [Jacinto Benavente $\uparrow]$

Briz (2017) distingue la formulación como estrategia preconcebida de la formulación inmediata por causas ajenas a la voluntad del hablante y expone que solo el primer tipo de formulación es intencional y comprende segmentos que constituyen actos y subactos. En esta investigación concebimos la función formulativa en un sentido amplio, como un efecto o manifestación de los procesos cognitivos de planificación y organización del discurso

14 Las almohadillas “\#\#" delimitan actos y las llaves " \{\} ”, los distintos tipos de subactos y subestructuras (Briz y Grupo Val.Es.Co. 2014: 67).

15 Para una definición de intensificación vid. Albelda (2007). 
sobre la marcha ${ }^{16}$, sin tener en cuenta si es estratégica (ej. adelanto del tópico) o no (ej. búsqueda de una palabra). Por ello, además de actos y subactos, incluimos los segmentos subestructurales que no llegan a constituir unidades estratégicas en sí, pero evidencian los procesos de construcción del discurso. No incluimos, en cambio, los truncamientos que se producen por contingencias extralingüísticas de la interacción, como el golpe en (11):

$$
\text { B: Con Jul- (GOLPE) ¡huy que lo rompo todo! Con Juliáan con David Vélez }
$$

\subsubsection{Atenuación}

Adoptamos la propuesta teórico-metodológica de Briz y Albelda (2013), en la que la atenuación se define como una estrategia pragmática de mitigación empleada intencionalmente por los hablantes para lograr intereses u objetivos comunicativos como el acuerdo o la aceptación del otro. Estos autores distinguen tres subfunciones específicas de atenuación:

\section{1) Autoprotección (salvaguarda del yo)}

Tiene por objeto "velar por uno mismo, no responsabilizarse o minorar responsabilidades, ser políticamente correcto a la hora de hablar de ciertos temas, de ciertas personas o instituciones, etc." (Briz y Albelda 2013: 302). En (12), B se interrumpe para aclarar, antes de proseguir su enunciación, que lo que proferirá a continuación no es machista (¡no machista!) y evitar ser calificado como tal:

(12) D: [a ver la definición de mujer $\rightarrow$ ]

B: [escúchame]// enn los genes de la mu- ¡no machista! en los genes [de la mujer] siempre está el deseo de tener BOLsos zapatos y vestidos

\section{2) Prevención (salvaguarda del yo y del tú)}

Pretende "prevenir posibles daños a la imagen o problemas por la intromisión o invasión del territorio o espacio del otro" (Briz y Albelda 2013: 302-303). En (13), ante un tema polémico sobre el que ambos interlocutores comparten opiniones distintas, B se interrumpe para introducir una fórmula ( $a$ ver si me entiendes joder) con la que trata de evitar un conflicto, consciente de que la afirmación que expresará a continuación es contraria a la opinión de $\mathrm{C}$ y puede causar daños a la imagen de su interlocutor $-\mathrm{y}$, por ende, a la propia-:

(13) C: [¿tú estás en contra del aborto?]

B: [sí]

C: [yo] estoy a favor

B: yo no/ yo en contra// tía pero bueno/ [eso es aparte]

C: [¿qué hago yo ahora] con un niño/ tía?

B: yoo o sea yo lo que decía es que- a ver si me entiendes joder/ yo/ un- una pareja// folla y se queda preñada $\uparrow$ se jode/ que tome $\uparrow$ medidas

16 A este respecto, es interesante considerar la definición de formulación de Pons (1998: 211-214), quien la considera una función pragmática relacionada con las dificultades de la planificación discursiva y con fenómenos como los reinicios, pausas sonoras, vacilaciones o cambios de proyecto sintáctico-semánticos. 
3) Reparación (salvaguarda del yo y del tú)

Se emplea cuando se ha producido un daño de imagen en la interacción y se pretende "[r]eparar una amenaza a la imagen del otro o una intromisión en el territorio del otro" (Briz y Albelda 2013: 303). En (14), A expresa que lo dicho por B es un poco mentira, pero se interrumpe al darse cuenta de que ha malinterpretado a su interlocutor y de que ha podido dañar su imagen:

(14) B: ¿tú te puedes creer Angelita $\rightarrow / /$ que en mi grupo de amigos de aquí $\rightarrow / /$ no haya un- un solo día que coincidamos $\mathrm{mm}$ sin tener algo $\uparrow\}$ para quedar $\uparrow$ en todo el verano?

A: ¿qué dices tío?///(1,42) ¡hombre! eso es un poco mentira ¿no? porque $\rightarrow$ jah! por culpa ((de los otros vamos que no será)) por ti

La propuesta metodológica de Briz y Albelda (2013) y Albelda et alii (2014) se basa en una ficha de análisis que permite interpretar y analizar cualitativa y cuantitativamente la función de atenuación: en primer lugar, se realiza una reflexión cualitativa preliminar del segmento para analizar el contexto situacional y el contexto interaccional concreto (CIC) ${ }^{17}$, la función y la forma lingüística del atenuante, y cualquier otro aspecto adicional relevante; a continuación, se lleva a cabo el análisis de las variables recogidas en la ficha, que son:

(A) Función general del atenuante (autoprotección, prevención o reparación).

(B) Tácticas lingüísticas o no lingüísticas ${ }^{18}$ de atenuación y número de procedimientos.

(C) Factores estructurales - posición discursiva del atenuante en relación al segmento atenuado y tipología textual de la intervención-.

(D) Factores enunciativos -relación entre el contenido de lo dicho y las imágenes de las personas, tipo acto de habla, etc.-.

(E) Factores situacionales -temática, finalidad, marco, relación vivencial de los interlocutores, datos sociolingüísticos, socioculturales, etc.--

La estructura truncada puede definirse como un procedimiento atenuador de elipsis de la conclusión, estructuras suspendidas o estructuras truncadas, o bien de movimiento de reformulación (Albelda et alii 2014), si bien puede aparecer junto con otras tácticas, como se verá más adelante (§ 4.2.). Conviene aclarar que, más que tratarse en sí de mecanismos atenuadores, los truncamientos son el efecto de una reorganización estratégica de la estructura sintáctica e informativa del discurso: la atenuación viene dada por los segmentos informativos o por otras tácticas (marcadores discursivos, elementos de justificación, reformulación) que se introducen mediante la acción de autointerrumpirse y reformular lo dicho. Todo truncamiento presenta una función formulativa de base, la cual puede subespecificarse como función atenuadora en contextos donde se pueda producir un daño a la imagen propia

17 El contexto interaccional concreto (CIC) hace referencia a los actos de habla o intervenciones previas y posteriores al segmento atenuante; está compuesto por tres segmentos: a) el causante de la atenuación, b) el atenuante -el recurso de atenuación- y c) el segmento atenuado. Incluye, también, el posible efecto que produce el atenuante (Briz y Albelda 2013: 300-302).

18 Albelda et alii (2014) describen un total de 22 tácticas que incluyen elementos morfológicos o léxicos, sintácticos, prosódicos, paralingüísticos o gestuales, etc. Estos recursos constituyen un listado no cerrado y pueden aparecer de forma aislada o conjunta. 
o ajena; sin embargo, la presencia de una táctica atenuante en una estructura truncada no siempre implica que el truncamiento sea una estrategia de atenuación. Por ejemplo, en (15) aparecen estrategias de atenuación (así gordete) independientes del truncamiento que se produce a continuación, que tiene una función formulativa:

(15) C: el otro día viene Marcos el de mi clase uno que es así gordete [con $\underline{\mathrm{mm}}$ barba $\uparrow$ y gafas $\uparrow$ ]

\subsection{Interrelación entre forma y función: algunas hipótesis}

Las hipótesis de las que parte este estudio son:

a. Los truncamientos de formulación superan en cantidad a los de atenuación, dado que la modalización es rica en recursos lingüísticos que permiten llevar a cabo estrategias de minimización sin que por ello se vea afectada la fluencia discursiva.

b. La duración del I es mayor en la formulación: el esfuerzo cognitivo que supone reorganizar el mensaje y solventar los problemas de la planificación sobre la marcha se plasma en un espacio de vacilación de mayor duración en el que el hablante gana tiempo para planificar su discurso.

c. La duración de la $\mathrm{R}$ es mayor en las estructuras de atenuación, dado que la reformulación del habla con fines atenuadores podría requerir un mayor despliegue de mecanismos verbales que la mera reorganización discursiva.

d. La velocidad de habla es menor en los EO de formulación, dado que el hablante puede detectar problemas ligados a la propia producción del habla (por ejemplo, la búsqueda de palabras) y, consecuentemente, ralentizar su tempo de elocución antes de interrumpirse para solucionarlos.

e. La velocidad de habla de la R supera a la del I, dado que el hablante retoma con normalidad el curso del habla tras el momento de vacilación, que podría enunciarse más lentamente debido a un mayor esfuerzo por planificar la continuación del discurso.

f. La F0 o la altura tonal perceptiva es menor en las R de atenuación, puesto que emplear un tono bajo podría ser un recurso prosódico ligado a salvaguardar la imagen propia o la ajena.

\section{METODOLOGÍA}

Para realizar este estudio se ha seleccionado aleatoriamente una muestra de 8 conversaciones ${ }^{19}$ del Corpus Val.Es.Co. 2.0 (Cabedo y Pons 2013). Las conversaciones tienen una duración total de 2.03 horas y una cantidad aproximada de 23.900 palabras. En primer lugar, se han identificado las intervenciones que contienen estructuras truncadas y se han segmentado en grupos entonativos y unidades, según la propuesta del modelo Val.Es.Co. (§ 2.2.2.). La segmentación ha permitido delimitar las fronteras estructurales internas y externas de los segmentos truncos, tomando como base las unidades acto, subacto y los segmentos subestructurales. Se han excluido los segmentos que carecen de alguna de las tres partes prototípicas del truncamiento (§ 2.2.1.), así como aquellos motivados por causas extralingüísticas (§ 2.3.1.).

19 Concretamente, las conversaciones n. ${ }^{\circ} 15,20,30,36,27,43,45$ y 46. 
En segundo lugar, se ha realizado el análisis acústico-perceptivo de los truncamientos mediante el programa Praat (Boersma y Weenink 2016). Se han analizado los siguientes rasgos suprasegmentales en los grupos entonativos que componen cada una de las regiones de la estructura trunca: duración (segundos), velocidad de habla (n. ${ }^{\circ}$ palabras/segundo), altura tonal perceptiva (alta, neutra o baja) y valor de F0 (hz) ${ }^{20}$. También se ha analizado la presencia de pausas (silenciosas o llenas) y su duración, así como la percepción de alargamientos e inflexiones tonales a final de sílaba, tanto en el punto de interrupción como en la transición del interregno a la reparación. Además del análisis prosódico, se ha prestado atención al tipo de elemento que conforma el interregno (partícula discursiva, pausa llena, subacto, etc.) con la finalidad de describir esta parte intermedia de las estructuras truncadas.

En tercer lugar, se ha realizado el análisis pragmático de las funciones de formulación y modalización de los truncamientos. Para ello, se ha partido del método propuesto por Briz y Albelda (2013) y Albelda et alii (2014) expuesto en 2.3.2.1. con el fin de discernir las funciones de atenuación frente a otras posibles funciones. Primero se ha llevado a cabo una reflexión cualitativa de los factores situacionales, contexto general y $\mathrm{CIC}^{21}$ de la intervención en la que se ubica cada truncamiento; en caso de identificar un posible daño de imagen y de reconocer alguna parte de la estructura truncada como el segmento discursivo desencadenante de la atenuación, afectado por la atenuación o como el propio atenuante, se ha procedido a clasificar el truncamiento como procedimiento de atenuación; en caso contrario, se la estructura se ha clasificado como truncamiento de formulación. Este análisis ha permitido observar que algunas estructuras pueden asociarse a mecanismos no tanto atenuantes, sino de intensificación; estos casos se han excluido del análisis. En segundo lugar, se ha realizado un análisis lingüístico de las estructuras con función de atenuación teniendo en cuenta las variables A y B de la ficha metodológica (§ 2.3.2.), esto es: A) la subfunción de atenuante específica de autoprotección, prevención o reparación del segmento y B) las diversas tácticas de atenuación presentes en la estructura.

Por último, la recopilación de los ejemplos en una base de datos con variables cuantitativas y cualitativas ha permitido cotejar los datos prosódicos y los pragmáticos para observar su posible interrelación.

\section{RESULTADOS}

Los siguientes subapartados describen las características de los datos analizados (§ 4.1.), las diferentes tácticas encontradas en los truncamientos atenuadores (§ 4.2.) y los rasgos prosódicos generales de las estructuras truncadas (§ 4.3.), referidos tanto a cada parte del truncamiento ( $\$ 4.3 .1$.), como a los momentos de transición entre las distintas partes -el punto de interrupción $(\S 4.3 .2)$ y el punto de transición del interregno a la reparación $(\S$ 4.3.3.)-.

20 El análisis de la F0 ha presentado limitaciones metodológicas por la presencia de habla solapada, ruidos, etc.: solo se ha podido analizar la F0 del EO, I y R en 19, 31 y 15 estructuras, respectivamente. Por otro lado, si bien los hablantes de las conversaciones son de diferente sexo y edad, para la extracción de los valores medios se han considerado todos conjuntamente. Por todo ello, se ha optado por incluir el criterio perceptivo de la altura tonal como dato complementario.

21 Vid. nota 17. 


\subsection{Descripción de los datos}

El corpus analizado contiene un total de 46 estructuras truncadas que responden a los criterios fijados para este estudio (§ 3). La Figura 3 ilustra la distribución de las estructuras según su función ${ }^{22}$ :

\begin{tabular}{|l|l|l|}
\hline Funciones & \multicolumn{2}{|l|}{ Recuento } \\
\hline formulación & 24 & \multirow{2}{*}{22} \\
\cline { 1 - 2 } atenuación_1 & 14 & \\
\cline { 1 - 2 } atenuación_2 & 5 & \\
\cline { 1 - 2 } atenuación_3 & 3 & \\
\hline Total general & $\mathbf{4 6}$ & \\
\hline
\end{tabular}

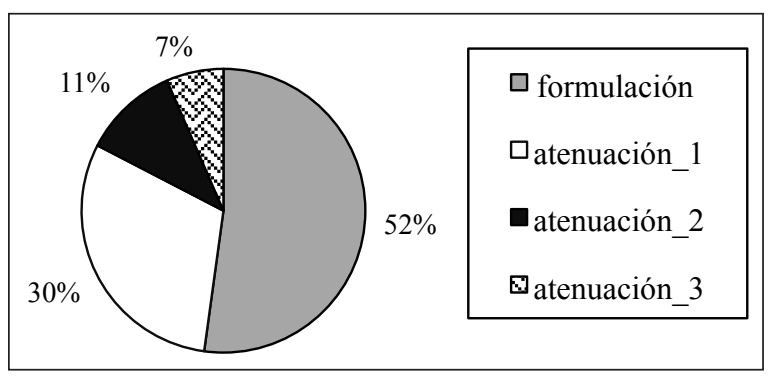

Figura 3. Distribución de las funciones de los truncamientos.

La distribución de las funciones formulativa (52\%) y atenuadora (48\%) es bastante equitativa. Dentro de las funciones de atenuación, predomina la de autoprotección (14 casos, el $63.5 \%$ del conjunto de funciones de atenuación y el $30 \%$ del conjunto total de funciones) frente a la preventiva (que representa el $23 \%$, el $11 \%$ de las funciones generales) y a la reparación (tan solo el $13.5 \%$ de las funciones de atenuación, el $7 \%$ de las funciones generales).

\subsection{Descripción de las tácticas de atenuación}

De los truncamientos estudiados, 6 son estrategias de atenuación de reformulación que no van acompañadas de otras tácticas. Por ejemplo, en (16), el hablante B, tras afirmar yo no querría, se interrumpe y reformula para evitar responsabilidades:

(16) B: sí// eeh no me estoy refiriendo ya por la otra persona que se acople a ti o se deje de [acoplar=] C: [yo no lo veo]

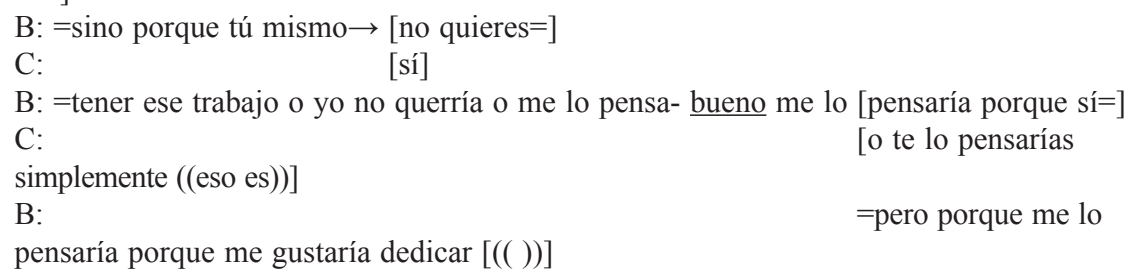

Los 16 truncamientos de atenuación restantes aparecen junto a una o varias tácticas lingüísticas de atenuación. Los recursos empleados (por orden de frecuencia) son los siguientes:

22 En la descripción de las funciones de atenuación se utiliza la numeración 1, 2 y 3 para las funciones de autoprotección, prevención y reparación, respectivamente. 
- Elementos de justificación o excusa (7 casos). En (17) E interrumpe su discurso para justificar su desconocimiento:

(17) E: \# \{pero $\}_{\mathrm{SAT}}\{\text { en la calle q-/ \#\{jes que }\}_{\mathrm{SAT}}\{\text { no sé cuál es!/ }\}_{\mathrm{SSD}} \#$ ¿la calle que va de la plaza América $\uparrow /$ a Cánovas? $\}_{\text {SSD }} \#$

- Partículas que regulan el contacto con el oyente (5 casos). En (18) aparece tía junto a una marca de fingimiento de incertidumbre (que yo qué sé):

(18) B: \# \{[y aparte $\}_{\mathrm{SAT}}\{\text { que- }\}_{\mathrm{SXX}} \# \#$ \{que yo qué sé $\}_{\mathrm{SAM}}\{$ tía $\left.]\right\}_{\mathrm{SAI}}$ \{que si supieras que es un chaval que luego va a venir a Valencia y todo el rollo $\}_{\text {SSD }}\{\text { aun así } \downarrow\}_{\text {SSS }} \#$

- Construcciones de duda o de fingimiento de incertidumbre (4 casos), como:

(19) Ed: \# \{[no/ $\}_{\mathrm{SAM}}\{$ igual está $]$ buení- $\left./\right\}_{\mathrm{SSD}} \# \#\{\text { yo no lo sé }\}_{\mathrm{SSD}}\{i \text { eh? }\}_{\underline{\mathrm{SAM}}}\{\text { pero }\}_{\mathrm{SAT}}\{$ igual está buenísimo $\uparrow /\}_{\mathrm{SSD}} \#$

- Construcciones concesivas (3 casos), como en (20). B argumenta que tener pareja implica más gastos, pero concede que hay gastos que se compartirían, como la vivienda:

(20) B: \# $\{\text { pero }\}_{\mathrm{SAT}}\{$ acabamos pagando $(($ aunque sea- $))]\{\underline{\text { vale }}\}_{\mathrm{SAT}}$ la casa entre los dos yy ((las)) cosas así $\}_{\text {SSD }}\{\text { pero }\}_{\text {SAT }}\{\text { es que }\}_{\text {SAT }}$ \{luego cada vez que salimos como el [GASTO COMO EL GASTO como el GASTO $\}_{\text {SSS }}$ \#

- Impersonalizaciones (3 casos). En (21) D pasa de describir lo que le sucede a un referente (de repente empezó a vomitar típico virus dee) a un interlocutor general (de que te da de repente un virus y te tiras [...]):

(21) D: \# \{no sé $\}_{\text {SSD }} \#$ \#\{de repente empezó a vomitar típico virus dee// \{de iyo qué sé! $\}_{\underline{S A M}}$ $\{\text { de quee } /\}_{\text {SSX }}$ de que te da de repente un virus $\}_{\text {SSD }}\{y$ te tiras dos días vomitaando y de cagaleras y todo $[(($ esto $))]\}_{\text {sss }} \#$

- Otros recursos como la aparición de partículas de objetivización (2 casos) o cuantificadores minimizadores ( 2 casos), como en (14), donde aparece un poco; o la presencia de difusores del significado (2 casos), como y todo esto, en el ejemplo previo (21).

\subsection{Rasgos prosódicos de las estructuras truncadas con funciones de formulación y atenuación}

\subsubsection{Enunciado originario, interregno y reparación}

La Tabla 2 muestra el valor medio de la duración, frecuencia fundamental (F0), altura tonal percibida y velocidad de habla de cada una de las partes de los 46 truncamientos analizados con función de formulación y atenuación. En el caso de la atenuación, se describen los rasgos específicos de las tres subfunciones. La Tabla 3 recoge el conjunto de elementos que aparecen en el interregno de las estructuras analizadas: 


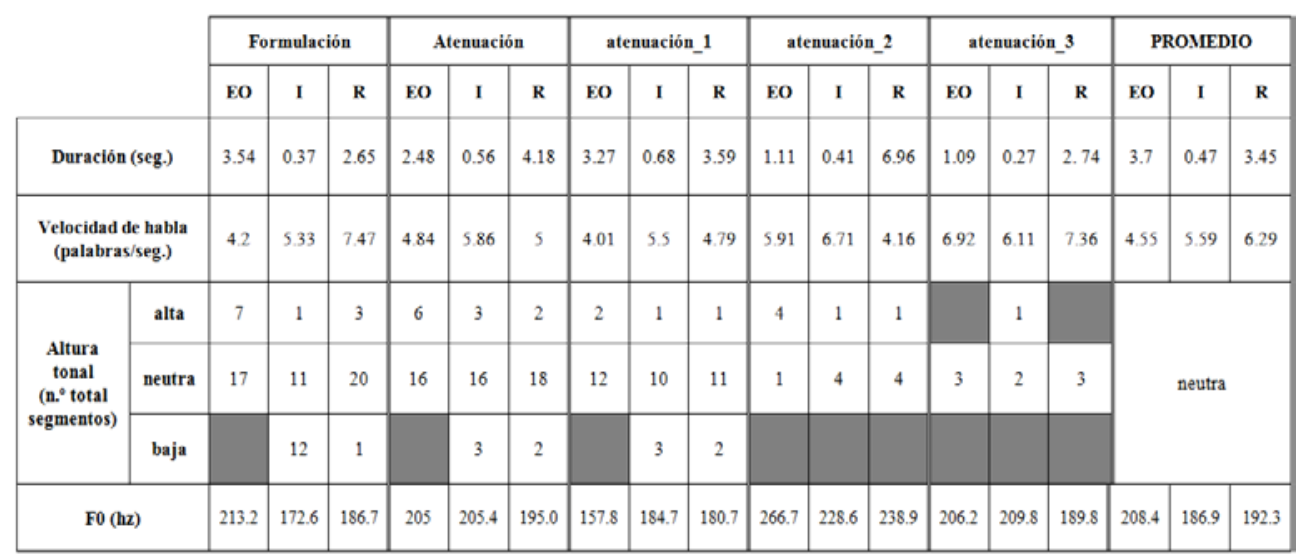

Tabla 2. Rasgos prosódicos de las estructuras truncadas ${ }^{23}$

\begin{tabular}{|c|c|c|c|c|c|c|c|c|}
\hline & \multicolumn{3}{|c|}{ Formulación } & \multicolumn{3}{|c|}{ Atenuación } & \multirow{2}{*}{\multicolumn{2}{|c|}{ TOTAL }} \\
\hline ELEMENTO & FORMA & TOT & & FORMA & & $\mathrm{AL}$ & & \\
\hline \multirow{6}{*}{ Partículas discursivas } & o sea & $5:$ & \multirow{6}{*}{9} & o sea & 4 & \multirow{6}{*}{12} & 9 & \multirow{6}{*}{21} \\
\hline & bueno & 1 & & bueno & 4 & & 5 & \\
\hline & $i a h !$ & 1 & & $\lceil a h !$ & 1 & & 2 & \\
\hline & digo & 1 & & a ver & 1 & & \multirow{3}{*}{5} & \\
\hline & \multirow{2}{*}{ claro } & \multirow{2}{*}{1} & & es que & 1 & & & \\
\hline & & & & vale & 1 & & & \\
\hline $\begin{array}{c}\text { Combinación de partículas } \\
\text { discursivas }\end{array}$ & & & & $\begin{array}{l}\text { bueno no, que yo qué } \\
\text { sé tía }\end{array}$ & & & \multicolumn{2}{|c|}{2} \\
\hline $\begin{array}{c}\text { Partícula discursiva y } \\
\text { subacto }\end{array}$ & & & & $\begin{array}{l}\text { pero no por mí, yo no } \\
\text { lo sé ¿eh?, a ver si } \\
\text { me entiendes joder, } \\
\text { noo ahora no lo sé }\end{array}$ & & & \multicolumn{2}{|c|}{4} \\
\hline $\begin{array}{l}\text { Particula discursiva y } \\
\text { repetición de elemento del } \\
\text { enunciado original }\end{array}$ & $\begin{array}{l}\text { o sea si nos } \\
\text { separamos }\end{array}$ & \multicolumn{2}{|c|}{1} & Es decir cariño & & & \multicolumn{2}{|c|}{2} \\
\hline \multirow{3}{*}{ Pausas llenas } & $\mathrm{hmm}$ & 4 & \multirow{3}{*}{14} & & & & 4 & \multirow{3}{*}{14} \\
\hline & eeh & 9 & & & & & 9 & \\
\hline & uuh & 1 & & & & & 1 & \\
\hline Subacto & & & & $\begin{array}{l}\text { De jyo qué sól, ino } \\
\text { machista!, jes que no } \\
\text { sé cuál es! }\end{array}$ & & & & \\
\hline
\end{tabular}

Tabla 3. Elementos del interregno

\subsubsection{Duración}

La duración de las partes EO y $\mathrm{R}$, de acuerdo con los valores medios, es muy similar, mientras que el I es, de media, $3.10 \mathrm{~s}$ más breve. Esto es coherente con el papel que desempeñan las partes del truncamiento: el EO y la $\mathrm{R}$ mantienen una relación semántico-

23 La casillas en gris indican que no han aparecido casos. 
estructural estrecha (la R reformula, sustituye, amplía o suprime -repara (vid. § 2.1.2.)- el EO); en cambio, el I es generalmente un segmento metalingüístico o procedimental que especifica la relación entre el EO y la R, por lo que no es de extrañar que sea más breve. Este patrón general se cumple en las funciones de formulación y atenuación; sin embargo, destacan algunas diferencias:

Los EO presentan una menor duración en los casos de atenuación; especialmente, las subfunciones 2 (1.11) y 3 (1.09) muestran segmentos más breves, lo cual podría indicar que el hablante se apresura a interrumpir cuanto antes el EO para prevenir y reparar, y no tanto para autoprotegerse. En todos los casos de atenuación, el EO tiene una duración menor que la R.

El I de los truncamientos de formulación es más breve que en los de atenuación -excluyendo el caso particular de la atenuación 3-, posiblemente porque más de la mitad de los elementos que componen este segmento en la formulación son pausas llenas. La duración del I en las subfunciones de atenuación tiene valores diversos, siendo el caso de atenuación 1 el más duradero (0.68) y el de 3 el menos (0.27). Ello se debe a que el I de atenuación 1 está formado en su mayor parte por subactos y el de atenuación 3, por la partícula o sea y la interjección ¡ah! El espacio de vacilación o hesitación es, contra toda intuición, mayor cuando se reformula el mensaje con fines atenuadores.

$\mathrm{La} \mathrm{R}$ en las estructuras de formulación es, de media, $1.53 \mathrm{~s}$ inferior a la $\mathrm{R}$ de las estructuras de atenuación; los valores de $\mathrm{R}$ varían bastante entre las subfunciones de atenuación: destaca la función 2, con una duración media de casi $7 \mathrm{~s}$. Todo ello indica que el hablante realiza un mayor despliegue verbal en la reelaboración de su discurso cuando está atenuando, específicamente cuando se trata de prevenir un posible enfrentamiento entre el yo y el tú.

\subsubsection{Velocidad de habla}

Las tres partes de las estructuras presentan valores semejantes -mantienen una diferencia de una o dos palabras pronunciadas por segundo-. En la función formulativa, igual que en los valores medios, la velocidad va aumentando a medida que se enuncia la estructura, siendo la $\mathrm{R}$ la parte que más rápidamente se pronuncia y el EO la que menos (con una diferencia de 3.27 palabras/segundo). En la atenuación no se observa esa progresión -a excepción del caso de la subfunción 3-: el I es la parte enunciada con mayor velocidad. La velocidad de la $\mathrm{R}$ es inferior a la del I (salvo en la subfunción 3, en la que la $\mathrm{R}$ se enuncia con mayor velocidad) y, en el caso de la atenuación 2, inferior también a la del EO. La diferencia entre el EO y la $\mathrm{R}$ en los casos de atenuación es de 0.16 palabras/segundo. Por lo general, la velocidad es levemente mayor en las tres regiones del truncamiento en las funciones de atenuación 2 y 3 .

\subsubsection{Altura tonal y F0}

La altura tonal que predomina en las tres partes es la neutra. Llaman la atención algunos casos con altura tonal alta en el EO, significativos en el caso de la atenuación 2, lo cual tiene un reflejo en los valores de F0 (266.7). En cuanto al I, destaca el elevado número de casos con altura tonal baja en la función de formulación (12 casos), lo cual se ve confirmado por los bajos valores de la F0 (172.66), así como la presencia de 3 casos en atenuación 1. Destaca también la aparición de un caso de altura tonal perceptivamente alta en el I de las funciones 
de atenuación 2 y 3, dado el escaso número de ocurrencias en ambas funciones. En la $\mathrm{R}$ predomina la altura tonal neutra, a excepción de algunos pocos casos de tonalidad baja -en formulación y atenuación 1-, y alta -tanto en funciones de formulación como de atenuación-.

Los valores de la F0 son bastante homogéneos en las tres partes de las estructuras. En las funciones de formulación y de atenuación 2, la F0 menor aparece en el I y la mayor en el EO, mientras que en el resto de funciones los valores máximos aparecen en el I y los mínimos en la R (atenuación 3) o en el EO (atenuación 1). Todo ello parece indicar que la F0 no es un rasgo determinante en la distinción de las funciones, tampoco de las tres partes que conforman las estructuras; la tonalidad baja asociada al I podría estar relacionada con su función más procedimental, especialmente en el caso de la formulación, en el que el I es de media más bajo (172.66), o en la atenuación 1 (184.75). Destaca, por el contrario, el valor más elevado del I en la atenuación 2 (228.6), aunque, perceptivamente, esta subfunción se considera neutra. Los valores de la $\mathrm{R}$, salvo en la atenuación 2 , son bastante similares entre las funciones.

El único rasgo distintivo que se advierte es la presencia de un tono más elevado en los truncamientos de atenuación 2, tanto acústica como perceptivamente. Parece que el tono es más elevado a la hora de prevenir problemas o daños de imagen.

\subsubsection{Elementos del Interregno}

La mayor parte de elementos son partículas discursivas ${ }^{24}$ aisladas o combinadas con otras partículas o elementos proposicionales (27 casos en total). Es frecuente hallar pausas llenas (14) y, en menor medida, segmentos (subactos) con contenido proposicional (3).

La presencia de una pausa llena es indicativa de la función formulativa y puede estar ligada a la necesidad de ganar tiempo durante los procesos cognitivos de planificación discursiva. En cambio, la aparición de un subacto (esto es, de un segmento informativo insertado), incluso si este va encabezado por una partícula discursiva, está estrechamente ligada con la función de atenuación. Las partículas discursivas se asocian a ambas funciones, si bien predominan notablemente en los contextos de atenuación. El uso de las dos partículas más frecuentes, bueno y o sea, aparece indistintamente en ambas funciones discursivas.

\subsubsection{El punto de interrupción}

La interrupción del EO que genera un grupo de entonación fragmentario puede producirse mediante los siguientes fenómenos:

\subsubsection{Interrupción del grupo de entonación (26 casos)}

Se interrumpe la curva melódica sin que aparezcan marcas prosódicas concretas; en ocasiones se produce una pausa final de duración muy breve (inferior a $200 \mathrm{~ms}$ ), como en la Figura $4^{25}$, que representa un fragmento del ejemplo (15):

24 Seguimos la definición de partícula discursiva que ofrece en el Diccionario de partículas discursivas del español (Briz, Pons y Portolés 2008). Para la consideración de digo como partícula discursa, vid. Benavent (2015). 25 Las figuras que representan la curva melódica se han extraído mediante el programa Praat (Boersma y Weenink 2016). En ellas aparece una fila con la transcripción segmentada en subactos (o varias filas, en caso de que haya más de un hablante) y otra final con la segmentación en sílabas. 


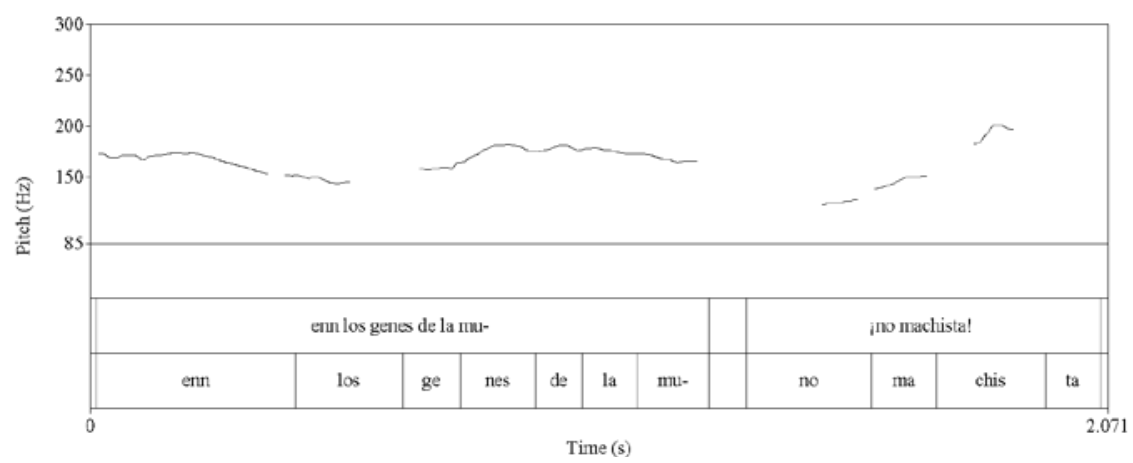

Figura 4. Pausa final de duración inferior a 200 ms.

\subsubsection{Alargamiento vocálico (5 casos)}

Se alarga la vocal final de la palabra previa a la interrupción, según ilustran la Figura 5 y (22) con porquee:

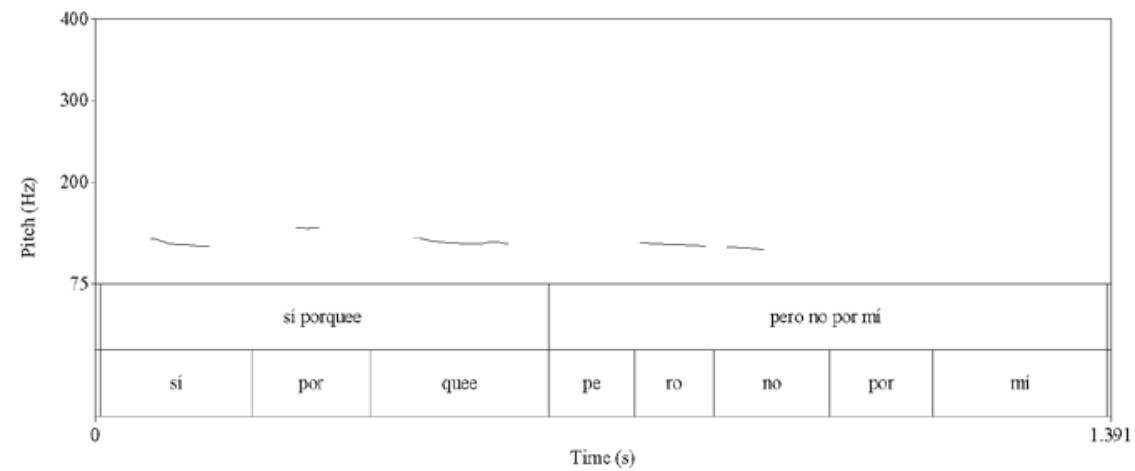

Figura 5. Alargamiento de la vocal final de la palabra previa a la interrupción.

(22) B: \# \{sí\} $\}_{\text {SSD }}\{\text { porquee- }\}_{\text {SSX }}\{\text { pero }\}_{\text {SAT }}$ \{no por mí $\}_{\text {SSS }}\{\text { porque las chicas sois así } \rightarrow\}_{\text {SSS }} \#$

\subsubsection{Inflexión tonal (5 casos)}

Se percibe una inflexión tonal marcada de tipo ascendente (23) o suspendida (24):

(23) M: \# \{pero $\}_{\mathrm{SAT}}\{\text { es- } /\}_{\mathrm{SXX}}\{\underline{\text { o sea }} /\}_{\mathrm{SAT}}\{[$ si tú haces algo $=]$

D: $\quad[(())]$

$\mathrm{M}:=$ mal $\uparrow\}_{\mathrm{SSs}}\{\underline{\text { eeh }}\}_{\text {Sxx }}\{\text { que te elijan o que no te lo elijan } /\}_{\mathrm{SSs}} /\{[\text { tendrás que pagarlo? }]\}_{\mathrm{SSD}} \#$ 
(24) E: \# \{tienes a la izquierda Tony Romas $/ /\}_{\mathrm{SSD}}\{\text { ¿vale } ? /\}_{\mathrm{SAI}}\{\mathrm{y}$ a la derecha hay un sitio que se 1 lama $\rightarrow /\{(\text { BALBUCEO }) /\}_{\text {SAT }}$ el quivalente $\rightarrow /\{\text { ee (BALBUCEO) } /\}_{\text {SAT }}$ hay un sitio que se llama/ el j- el Jamónn/ Cinco Jotas $[(())]\}_{\text {sss }} \#$

\subsubsection{Inflexión tonal y pausa (5 casos)}

Se percibe un tonema ascendente (Figura 6) o suspendido (Figura 7) seguido de pausa, la cual tiene una duración media de 1.52 segundos.

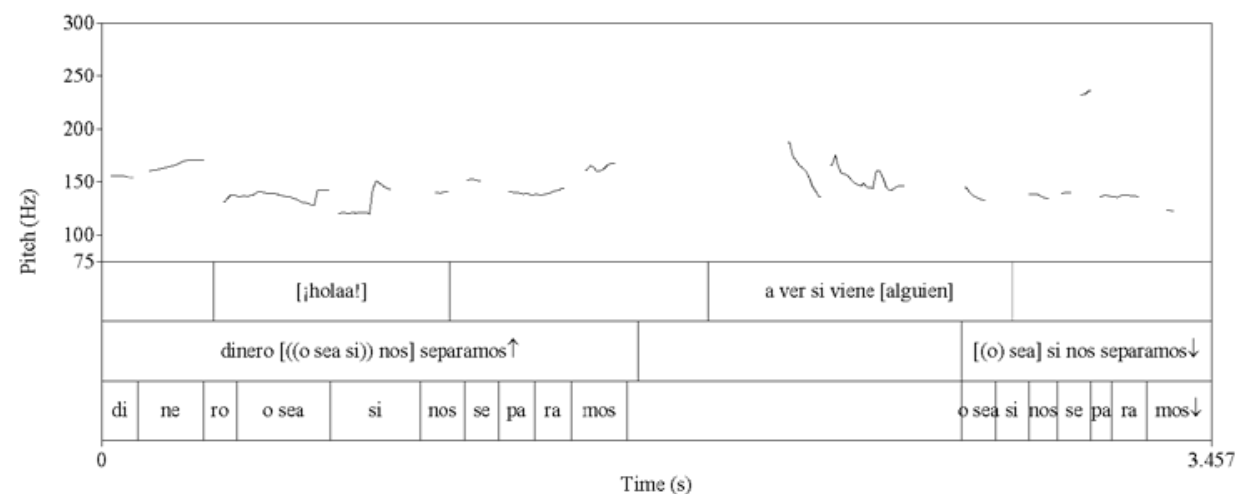

Figura 6. Tonema ascendente.

(25) B: \# \{ivale vale! $/ /\}_{\mathrm{SAI}}\{[\text { pues }(())]\}_{\mathrm{SAT}}\{[\text { no }(())((\text { me refiero }))]((\text { cae en lastre }))\}_{\mathrm{SSD}}$ \{pero si yo tengo mi dinero $\}_{\mathrm{SSS}}\left\{\left[\left((\text { o sea }\}_{\underline{\mathrm{SAT}}}\{\mathrm{si})\right)\right.\right.$ nos $\left.=\right]$

A: $\{[i \text { holaa! }]\}_{\text {SSD }}$

$\mathrm{B}:=\underline{\operatorname{separamos} \uparrow}\}_{\underline{S \mathrm{SD}}}$

A: $\{\text { a ver si viene [alguien] }\}_{\text {SSD }}$

B: $\quad\{[(0) \text { sea }]\}_{\underline{S A T}}\{\text { si nos separamos } \downarrow\}_{\text {SSS }}\{\text { si nos juntamos }\}_{\text {SSS }}$ \{pagamos just- $\}_{\mathrm{SSX}}\{\text { todo tal como todo va en gastos } \uparrow\}_{\mathrm{SSD}} \#$

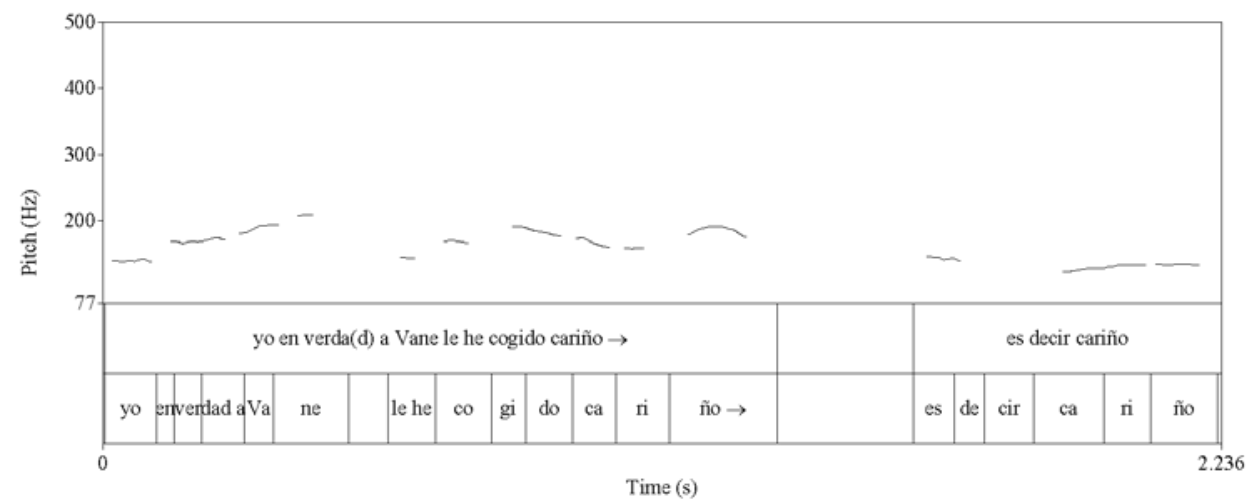

Figura 7. Tonema suspendido. 
(26) A: \# \{yo en verda(d) a Vane le he cogido cariño $\rightarrow /\}_{\text {SSD }}\{\underline{\text { es decir }}\}_{\text {SAT }}\{\text { cariño }\}_{\text {SSS }}\{$ yo la aprecio un montón a raíz de que vaya con vosotras $\}_{\mathrm{sss}} \#$

\subsubsection{Pausa (3 casos)}

La pausa de la interrupción tiene una duración media de 0.39 segundos (Figura 8).

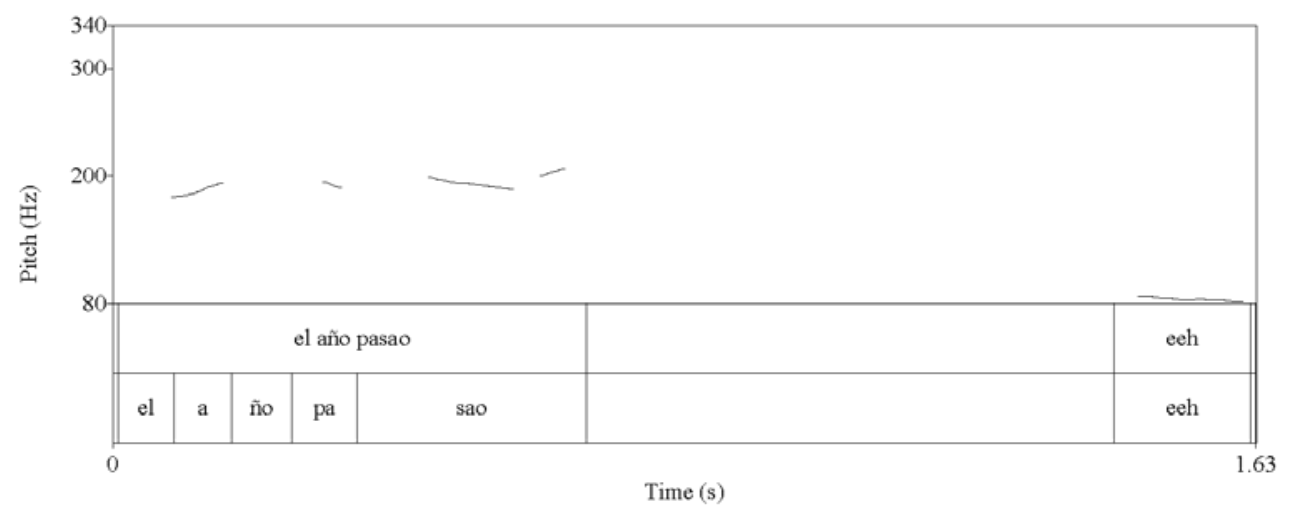

Figura 8. Pausa de la interrupción: duración media de 0.39 segundos.

(27) E: \# \{pues $\}_{\text {SAT }}\{\text { ya lo sé/ }\}_{\text {SSD }}$ \{pero es que el año [pasao] $\uparrow$ el a- el año pa- el año pasao// $\{\mathrm{ee} /\}_{\mathrm{SAT}}$ íbamos a ir aa $\left.\rightarrow\right\}_{\mathrm{SSS}}\{\text { cayóo } \rightarrow / \text { el veintiocho de diciembre } /\}_{\mathrm{SSS}} \#$

\subsubsection{Alargamiento vocálico y pausa (2 casos)}

La duración media de la pausa es de 1.39 segundos (Figura 9).

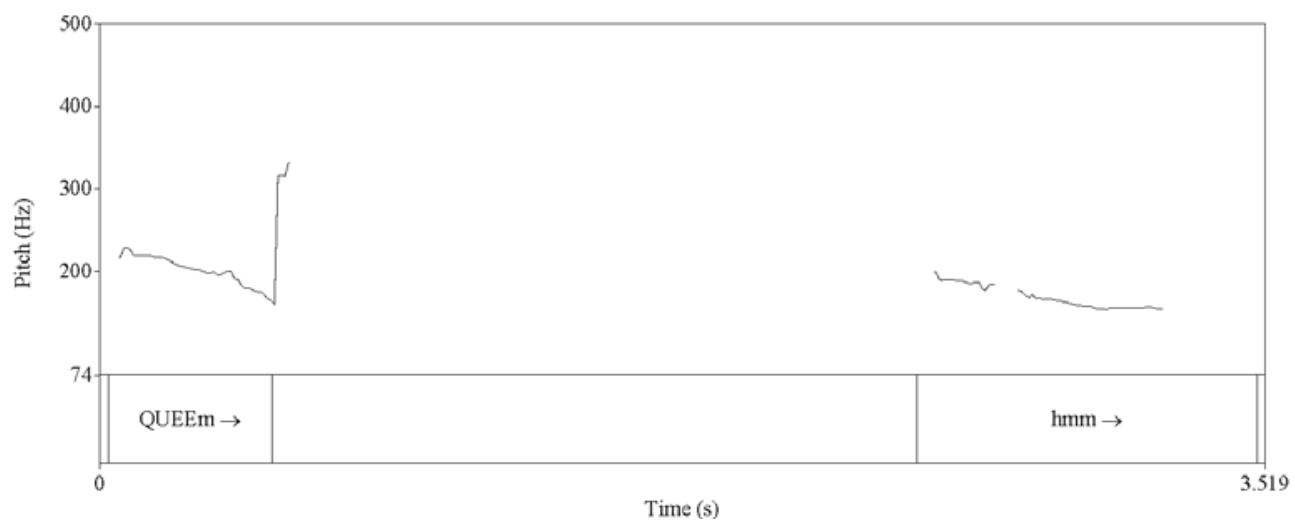

Figura 9. Alargamiento vocálico y pausa.

(28) A: \# $\{\mathrm{QUEEm} \rightarrow / / /\}_{\mathrm{SXX}}(1,88)\{\underline{\mathrm{hmm} \rightarrow}\}_{\mathrm{SAT}}\{\text { iqué ibas a decir }\}_{\mathrm{SSD}}\{\text { tío?// }\}_{\mathrm{SAI}} \#$ 
Los fenómenos prosódicos que aparecen en el punto de interrupción no parece ser muy relevantes para distinguir las funciones de formulación y atenuación (Figura 10):

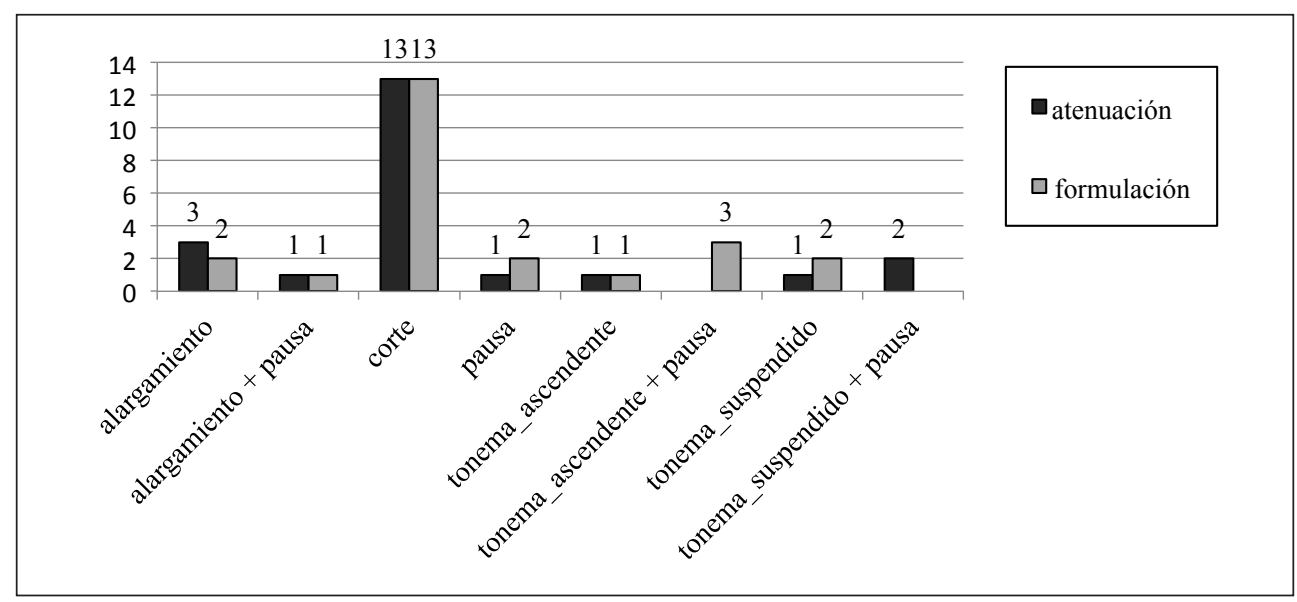

Figura 10. Fenómenos del punto de interrupción.

Si bien la aparición de un tonema ascendente seguido de pausa al final del EO puede parecer propia de la formulación (3 casos frente a ninguno de atenuación), puede verse que hay un caso de atenuación que se asocia también con un tonema ascendente, aunque sin pausa; lo mismo sucede con el tonema suspendido seguido de pausa: podría vincularse a la atenuación, pero aparece un tonema suspendido en un segmento con función atenuadora. La duración media de las pausas de interrupción sí podría ser indicadora, en cambio, de una u otra función (Tabla 4):

\begin{tabular}{|l|l|l|}
\hline Elemento & \multicolumn{1}{|c|}{ Formulación } & \multicolumn{1}{c|}{ Atenuación } \\
\hline Pausa & 0,76 & 0,44 \\
\hline Alargamiento + pausa & 1,88 & 0,90 \\
\hline Tonema ascendente + pausa & 2,19 & \\
\hline Tonema suspendido + pausa & & 0,51 \\
\hline
\end{tabular}

Tabla 4. Duración media de las pausas del punto de interrupción.

Las pausas son más largas en los truncamientos de formulación, lo cual puede implicar que el hablante necesita más tiempo antes de enunciar la reparación, dado el esfuerzo de procesamiento cognitivo que supone reorganizar su mensaje.

\subsubsection{La transición del interregno a la reparación}

En la transición del interregno hacia la reparación pueden darse los siguientes fenómenos: 


\subsubsection{Transición fluida (27 casos)}

Ningún elemento prosódico específico marca la transición (Figura 11):

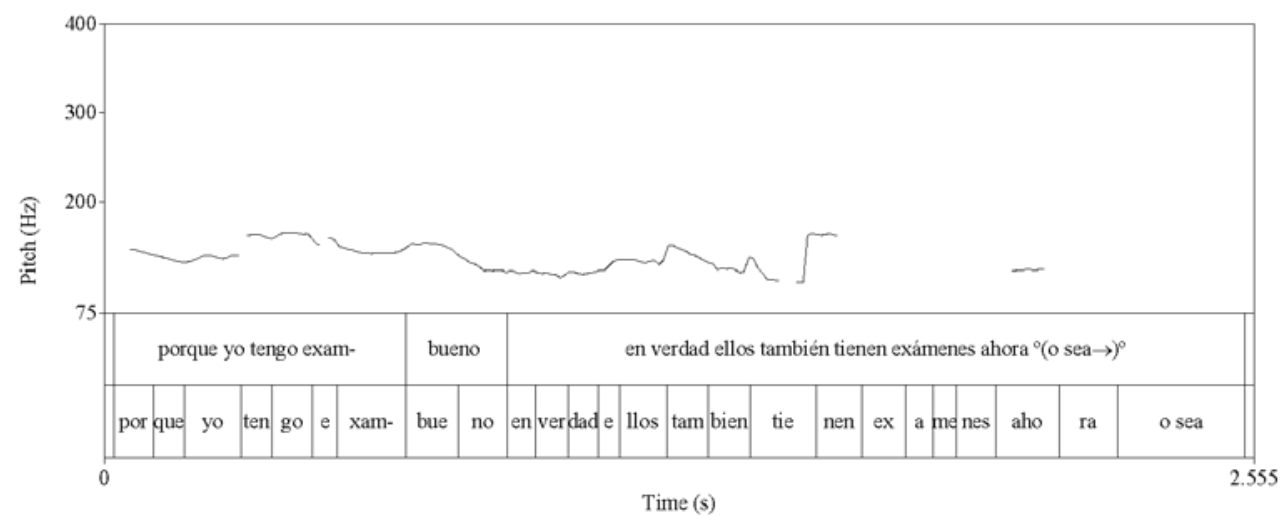

Figura 11. Transición fluida.

(29) B: \# (SUSPIRO)// $\{\text { un poco de cada }\}_{\text {SSD }}(2,61)\{\text { porque yo tengo exam- }\}_{\text {SSS }}\{\underline{\text { bueno }}\}_{\underline{S A T}}\{$ en verdad ellos también tienen exámenes ahora $\}_{\mathrm{SSS}}{ }^{\circ}\left\{(\mathrm{o} \mathrm{sea} \rightarrow)^{\mathrm{o}} / / /\right\}_{\mathrm{SAM}} \#$

\subsubsection{Pausa llena (13 casos)}

Aparecen pausas llenas como ee o mm (Figura 8 y Figura 9) que tienen una duración media de $0.40 \mathrm{~s}$, siendo la duración máxima $1.03 \mathrm{~s}$ y la mínima $0.06 \mathrm{~s}$.

\subsubsection{Pausa (3 casos)}

La duración media de la pausa es de 0.43 segundos (Figura 12).

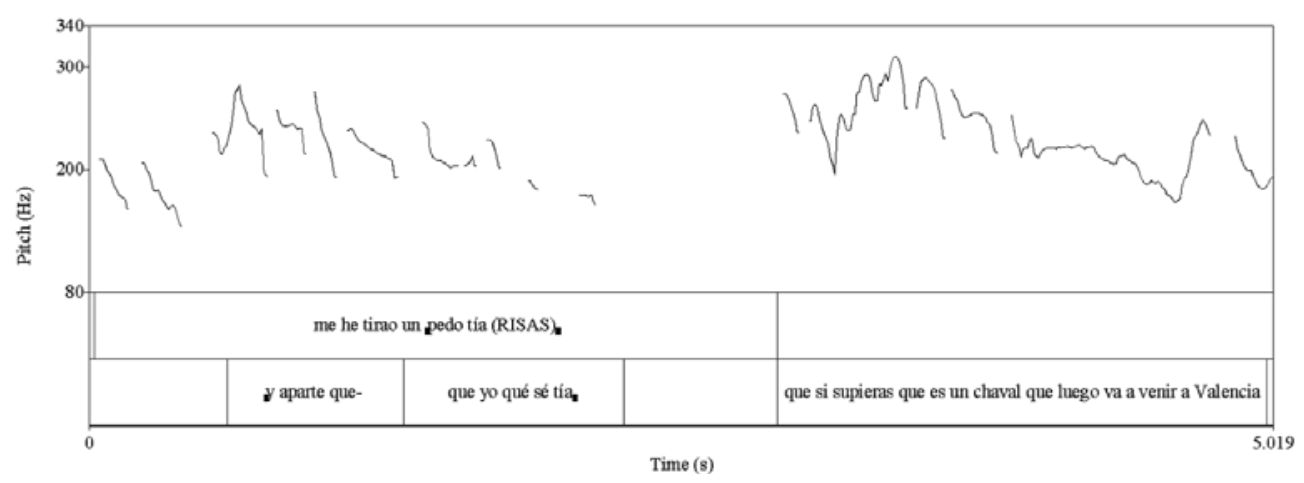

Figura 12. Pausa. 
(30) C: \# $\{$ me he tirao un [pedo tía (RISAS) $]\}_{\text {SSD }} \#$

B: \# $\left\{[\text { y aparte }\}_{\mathrm{SAT}}\{\text { que- }\}_{\mathrm{SXX}}\{\text { que yo qué sé }\}_{\mathrm{SAM}}\{\text { tía }] / /\right\}_{\mathrm{SAI}}$ \{que si supieras que es un chaval que luego va a venir a Valencia y todo el rollo $[\ldots]\}_{\text {SSD }}$

\subsubsection{Tonema descendente (2 casos) (Figura 13)}

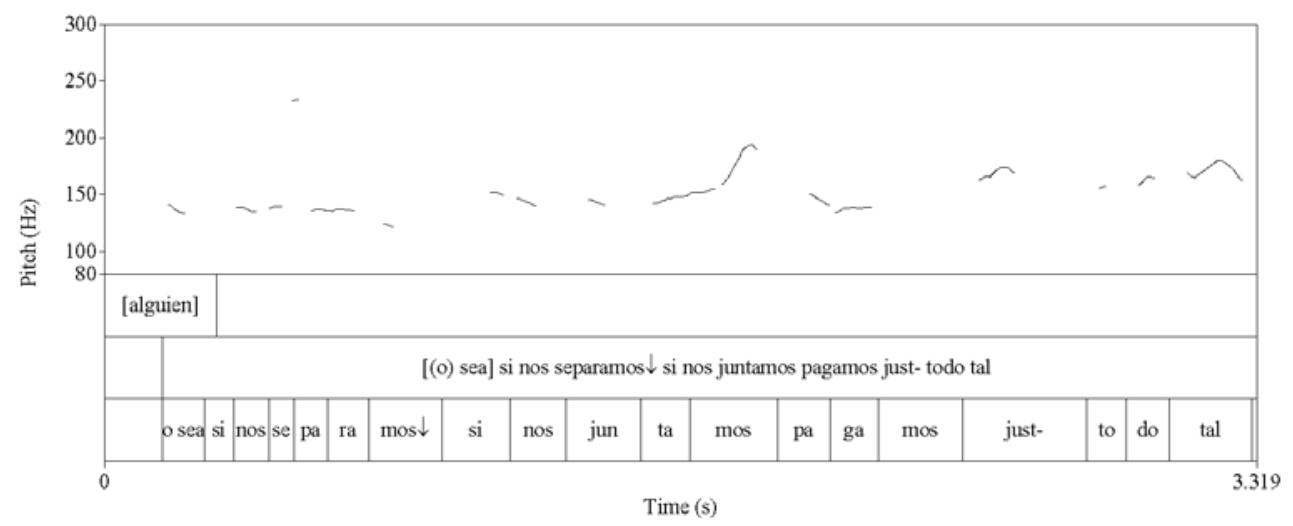

Figura 13. Tonema descendente.

\subsubsection{Pausa llena y pausa ( 1 caso)}

Tras la pausa llena aparece una pausa silenciosa de 0.43 segundos (Figura 14):

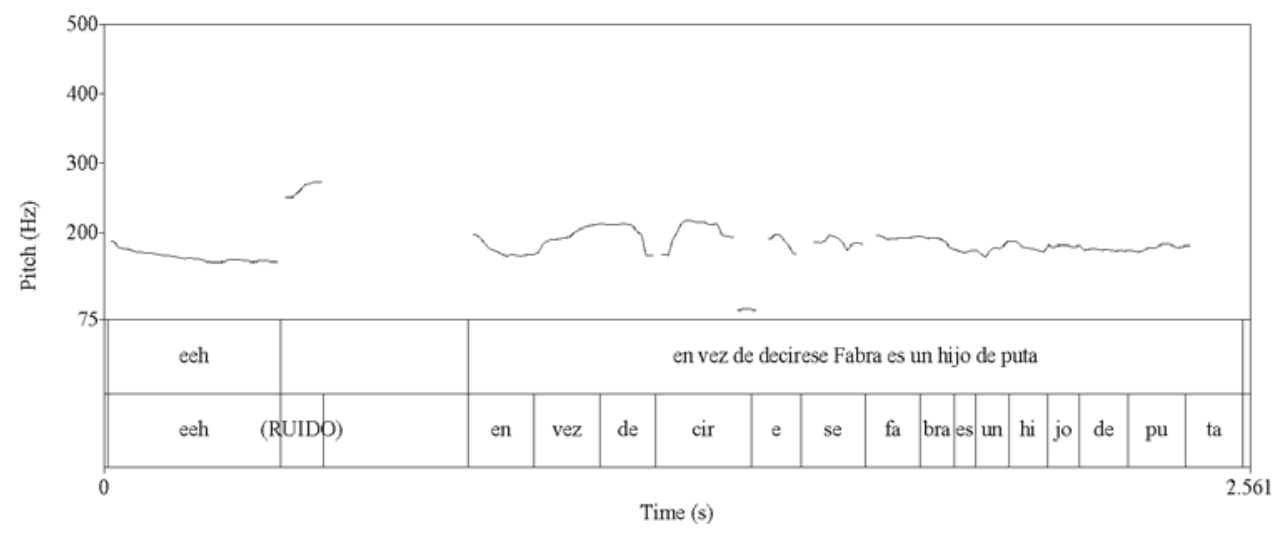

Figura 14. Pausa llena y pausa.

(31) Ed: \# \{que $/\}_{\text {SXX }}\{\text { eeh } /\}_{\text {SAT }}\{\text { en vez de decir/ ese Fabra es un hijo de [puta }=\}_{\text {SSD }}$ $\mathrm{E}$ :

[(RISAS)]

Ed: $\{=\text { lo que tienen] que hacer es meterlo en la cárcel }\}_{\mathrm{SSS}} \#$ 
La relación entre estos datos y las funciones puede observarse en la Figura 15:

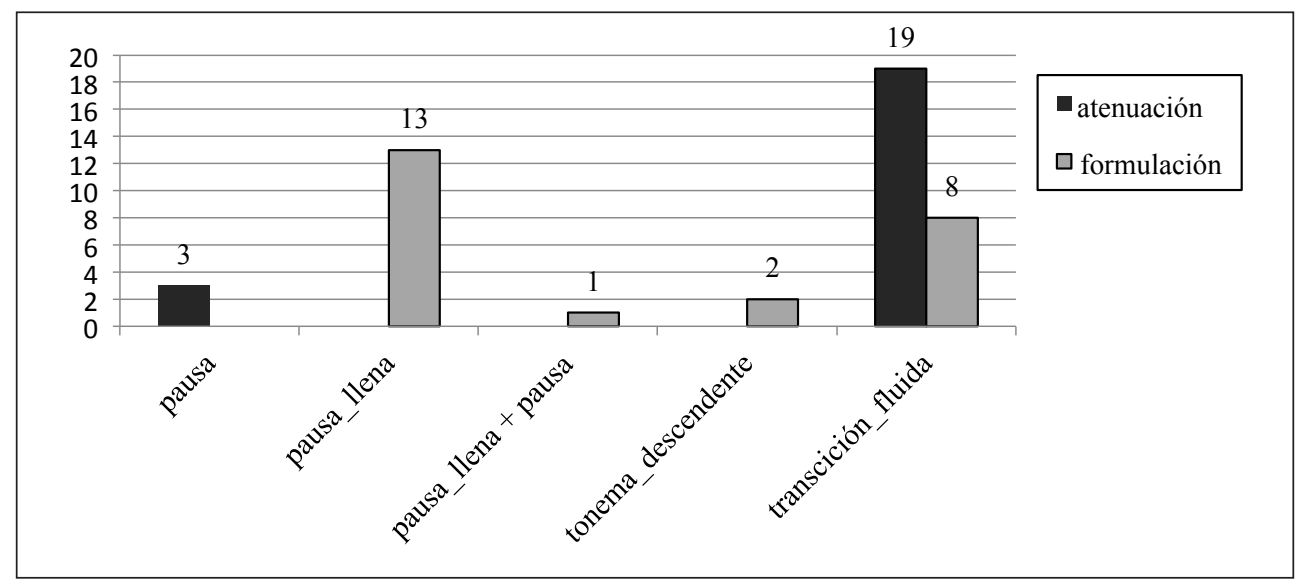

Figura 15. Fenómenos de transición del I a la R.

Las pausas llenas aparecen estrechamente ligadas a la función de formulación (recuérdese que es el principal componente del I); también los dos casos de tonemas descendentes se vinculan con la formulación. En cambio, las tres pausas silenciosas que aparecen tras el I, y cuya duración media es similar a la de las llenas, van asociadas a la función de atenuación. Las transiciones fluidas aparecen en estructuras truncadas con función formulativa y atenuadora, si bien predominan en esta última.

\section{SÍNTESIS Y CONCLUSIONES}

El objetivo de este estudio es comprobar si los rasgos prosódicos de los truncamientos permiten discernir las funciones discursivas de formulación o de atenuación. Aunque la representatividad de los resultados obtenidos está ligada a la muestra de datos analizada, se pueden extraer algunas conclusiones relevantes para el estudio de estas estructuras.

\subsection{Resultados generales}

El análisis de las funciones pragmáticas en el conjunto de estructuras truncadas muestra una distribución equitativa de las funciones de formulación $(52 \%)$ y atenuación (48 \%). A este respecto, queda descartada la hipótesis a) dado que los truncamientos de formulación no superan en gran cuantía a los de atenuación. En las funciones de atenuación, más concretamente, la función 1 de autoprotección es la que adquiere mayor representatividad $(63.5 \%)$, seguida de la función 2 de prevención (23\%) y de la 3 de reparación (13.5\%).

Las estructuras truncadas atenuadoras suelen aparecer junto con otras tácticas de atenuación (solo en 6 casos son estructuras atenuadoras per se), entre las más frecuentes se encuentran elementos de justificación o excusa ( 7 casos), partículas fático-apelativas ( 5 casos) y construcciones de duda o de fingimiento de la incertidumbre (4 casos). El marco 
metodológico adoptado (Briz y Albelda 2013, Albelda et alii 2014) se adapta perfectamente a las necesidades de este trabajo y ha permitido llevar a cabo el estudio de la atenuación.

En síntesis, los hablantes de las conversaciones estudiadas se autointerrumpen frecuentemente para formular o atenuar su discurso, y cuando atenúan, lo hacen en gran medida para autoprotegerse justificándose, buscando la complicidad del otro o fingiendo o expresando duda.

\subsection{Rasgos prosódicos y funciones pragmáticas}

En relación con la pregunta de investigación principal, ninguno de los rasgos suprasegmentales estudiados permite identificar de forma exclusiva las funciones de formulación y atenuación en las estructuras truncadas, aunque algunos resultados apuntan hacia la distinción entre ambas funciones. Los elementos prosódicos presentes en los puntos de transición entre las partes de la estructura parecen ser más indicativos de una u otra función.

\subsubsection{Duración, velocidad de habla, altura tonal y F0}

Los hablantes se apresuran más a interrumpirse y a reelaborar lo dicho, produciendo EO poco duraderos, cuando atenúan para prevenir y reparar daños a la imagen. El espacio de vacilación es mayor cuando reformulan su mensaje con fines atenuadores, lo cual desmiente la hipótesis b); esto podría indicar que el cambio de plan discursivo con fines atenuadores requiere mayor tiempo y esfuerzo cognitivo que el proceso de formulación, pero lo cierto es que el I en estos casos está constituido por subactos insertados, mientras que en los casos de formulación, está formado por pausas o partículas discursivas, de lo cual pueden derivarse estas diferencias duracionales. Por otro lado, los hablantes elaboran discursos más duraderos (aparentemente con un mayor despliegue verbal) al retomar su discurso tras la interrupción, en la $\mathrm{R}$, cuando atenúan, especialmente cuando tratan de prevenir un posible conflicto, lo cual confirma la hipótesis c).

En cuanto a la velocidad de habla, podría decirse que los hablantes, cuando retoman su discurso tras interrumpirse por causas de formulación discursiva, aumentan su tempo de elocución, especialmente en la R. El EO es, en la mayoría de casos, la parte enunciada con menor velocidad; esto tiene sentido, dado que es la parte en la que se detectan los problemas en la producción del habla y que, consecuentemente, se interrumpe. La velocidad del I suele ser superior a la del EO (salvo en el caso de atenuación 3) y a la de la R, siendo este último caso particular de las funciones de atenuación (a excepción de la subfunción 3). Estos datos confirman parcialmente las hipótesis d) y e) sobre la reducción de la velocidad de habla en los EO de formulación, y como se ha podido ver, también de atenuación, y su posterior aumento al retomar la fluencia discursiva en la R. Así pues, los hablantes podrían ralentizar su tempo al detectar problemas relacionados con la formulación discursiva o la reparación de un daño de imagen y tener que planificar y construir de nuevo el discurso; por otro lado, la velocidad aumenta una vez solucionan dichos problemas en la $\mathrm{R}$.

La altura tonal predominante es la neutra, si bien las estructuras formulativas se caracterizan por tener un alto número de casos de I con tono bajo. Queda descartada la hipótesis f) en relación con la altura tonal inferior de la $\mathrm{R}$ en los casos de atenuación, si bien los valores de la F0 muestran un leve descenso en los datos generales de la función de atenuación. La 
distribución de la F0 lleva a pensar que no es un rasgo determinante en la distinción de las funciones, tampoco de las tres partes que conforman las estructuras; el valor bajo de F0 en los I de formulación podría relacionarse con la función procedimental que desempeña el I, pero también con la alta presencia de pausas silenciosas y de segmentos breves en esta región. El rasgo más llamativo es el tono más elevado en las tres partes de los truncamientos de atenuación 2, sobre todo en el EO, lo cual apunta a una elevación mayor del tono a la hora de prevenir problemas o daños de imagen.

\subsubsection{Interregno}

El interregno de los truncamientos está conformado, mayoritariamente, por partículas discursivas (frecuentemente los reformuladores bueno y o sea) que aparecen aisladas o en combinación con otras partículas o subactos con contenido proposicional ( 27 casos). Las pausas llenas son el segundo elemento más frecuente (14 casos). La presencia de una pausa llena es indicativa de la función de formulación, mientras que la aparición de un subacto está estrechamente ligada con la función de atenuación. Las partículas discursivas aparecen vinculadas a ambas funciones.

\subsubsection{Punto de interrupción y punto de transición de I a $R$}

Lo habitual tanto en formulación como en atenuación es que la transición entre las distintas partes de la estructura no esté marcada prosódicamente, si bien es no es raro hallar alargamientos e inflexiones en el punto de interrupción y pausas llenas entre el I y la R. Los elementos del punto de interrupción no permiten distinguir la función formulativa de la atenuadora; sí parece ser relevante, en cambio, la duración de las pausas que pueden aparecer en el punto de interrupción, ya que las más largas están vinculadas a la formulación. En cuanto al espacio de transición del I a la $\mathrm{R}$, destaca la representatividad de las pausas llenas (y, en menor grado, de los tonemas descendentes) como índices de la función de formulación. Las pausas silenciosas aparecen más vinculadas a la atenuación.

En definitiva, el hablante emite pausas más largas cuando se interrumpe para formular que cuando lo hace para atenuar, tal vez porque la interrupción de formulación requiere mayor esfuerzo cognitivo antes de enunciar el I y la R. En la transición del I a la R, si el hablante emite una pausa llena o si el I presenta una inflexión tonal descendente, se tratará de un truncamiento de formulación, mientras que si realiza una pausa silenciosa es probable que el truncamiento sea de atenuación.

\section{Referencias bibliográficas}

Albelda, M. (2007). La intensificación como categoría pragmática: revisión y propuesta. Frankfurt am Main: Peter Lang.

Albelda, M., Briz, A., Cestero, A. M., Kotwica, D. y C. Villalba (2014). "Ficha metodológica para el análisis pragmático de la atenuación en corpus discursivos del español. ES.POR.ATENUACIÓN, Oralia, 17, pp. 7-62.

Álvarez, A. y M. A. Blondet (2003). "Cortesía y prosodia: un estudio de la frase cortés en el español de Mérida (Venezuela)”. En Martín Butragueño, P. y Z. E. Herrera (eds.). La tonía. Dimensiones fonéticas y fonológicas. México: El Colegio de México, pp. 319-330. 
Bedmar, M. J. (1987). "El anacoluto en la lengua hablada". En Amistad a lo largo. Estudios en Memoria de Julio Fernández Sevilla y Nicolás Marín López. Granada: Universidad de Granada, pp. 56-80.

Bedmar, M. J. y F. Pose (2007). "Sobre análisis del discurso y sintaxis de la comunicación. A propósito del estudio de las estructuras truncadas en el corpus PRESEEA-Granada". En Moya Corral, J. A. y M. Sosinski (eds.). Las hablas andaluzas y la enseñanza de la lengua. Actas de las XII Jornadas sobre la enseñanza de la lengua Española. Granada: Universidad de Granada, pp. 137-167.

Bedmar, M. J. y F. Pose (2008). "Análisis morfofuncional-comunicativo de las construcciones anacolúticas”. En Moya Corral, J. A. y M. Sosinski (eds.). El español en los territorios bilingües. Actas de las XIII Jornadas sobre la lengua española y su enseñanza. Granada: Universidad de Granada, pp. 167- 187.

Beinhauer, W. (1978). El español coloquial. Madrid: Gredos.

Benavent, E. (2015): Decir y discurso directo en los relatos de la conversación coloquial. Valencia: Universitat de València.

Boersma, P. y D. Weenink (2016). Praat. Doing phonetics by computer: http://www.praat.org/ (15-04-2016). Briz, A. (1998). El español coloquial en la conversación: esbozo de pragmagramática. Barcelona: Ariel.

Briz, A. (2017). "Los mal llamados 'cortes sintácticos' de la conversación coloquial”. Il confronto letterario, 66, pp. 13-34.

Briz, A. y A. Hidalgo (2008). "Marcadores discursivos y prosodia: observaciones sobre su papel modalizador atenuante”. En Briz, A., Hidalgo, A., Albelda, M., Contreras, J. y N. Hernández Flores (eds.). Cortesía y conversación: de lo escrito a lo oral. III Coloquio Internacional del programa EDICE. Valencia: Universitat de València/Programa EDICE , pp. 390-409: http:/www.edice.org/ descargas/3coloquioEDICE.pdf (15/04/2016).

Briz, A. y Grupo Val.Es.Co. (2003). "Un sistema de unidades para el estudio del lenguaje coloquial”, Oralia, 6, pp. 7-61.

Briz, A. y Grupo Val.Es.Co. (2014). "Las unidades del discurso oral. La propuesta Val.Es.Co. de segmentación de la conversación (coloquial)", Estudios de Lingüistica del Español, 35, 1, pp. 11-71: http://www.raco.cat/index.php/Elies/article/viewFile/285724/373695 (15/04/2016).

Briz, A. y M. Albelda (2013). "Una propuesta teórica y metodológica para el análisis de la atenuación lingüística en español y portugués. La base de un proyecto en común (ES.POR.ATENUACIÓN)", Onomazein, 28, pp. 288-319.

Briz, A., Pons, S. y J. Portolés (coords.) (2008). Diccionario de partículas discursivas del español: http://www.dpde.es.

Cabedo, A. (2009). Segmentación prosódica en la conversación coloquial: sobre el grupo entonativo como mecanismo demarcativo de unidades mínimas. Valencia: Universitat de Valencia.

Cabedo, A. (2011). "Hacia un modelo predictivo para la segmentación prosódica del discurso oral coloquial: MESTEL (Modelo Estadístico para la Selección de Términos Entonativos Ligados)”, Oralia, 14, pp. 85-104.

Cabedo, A. (2014). "On the delimitation of discursive units in colloquial Spanish: Val.Es.Co application model”. En Pons, S. (ed.). Discourse Segmentation in Romance Languages. Ámsterdam/ Filadelfia: John Benjamins, pp. 157-183.

Cabedo, A. y S. Pons (eds.) (2013). Corpus Val.Es.Co 2.0: http://www.valesco.es/?q=es/corpus (15-04-2016).

Chafe, W. L. (1993). "Prosodic and Functional Units of Language". En Edwards, J. A. y M. D. Lampert (eds.). Talking Data: Transcription and Coding in Discourse Research. Hillsdale (New Jersey): Lawrence Erlbaum Associates, pp. 33-43.

Devís, E. (2011a). “La entonación de (des)cortesía en el español coloquial”, Phonica, 7, pp. 36-79.

Devís, E. (2011b). "Rasgos melódicos de la cortesía atenuadora en el español coloquial”, Moenia, 17, pp. 475-490.

Haverkate, H. (1994). La cortesía verbal. Estudio pragmalingüístico. Madrid: Gredos.

Herrero, G. (1995). "Sobre construcciones fragmentadas", Philologia Hispalensis, 10, pp. 99-113. 
Hidalgo, A. (2001). "Modalidad oracional y entonación. Notas sobre el funcionamiento pragmático de los rasgos suprasegmentales en la conversación”, Moenia, 7, pp. 271-292.

Hidalgo, A. (2006). "La expresión de cortesía (atenuación) en español hablado: marcas y recursos prosódicos para su reconocimiento en la conversación coloquial". En Villayandre, M. (ed.). Actas del XXXV Simposio Internacional de la SEL. León: Universidad de León, pp. 958-979.

Hidalgo, A. (2007). "Sobre algunos recursos fónicos del español y su proyección sociopragmática: atenuación y cortesía en la conversación coloquial", Quaderns de Filologia: Estudis Lingüistics, 12 , pp. $129-152$.

Hidalgo, A. (2009). "Modalización (des)cortés y prosodia: estado de la cuestión en el ámbito hispánico", Boletín de Filología de la Universidad de Chile,44, 1, pp. 161-195.

Hidalgo, A. y X. Padila (2006). "Bases para el análisis de las unidades menores del discurso oral: los subactos", Oralia, 9, pp. 109-143.

Levelt, W. J. M. (1983). "Monitoring and self-repair in speech", Cognition, 12, pp. 41-104.

Narbona, A. (1992). "Hacia una sintaxis del español coloquial". En Actas del Congreso de la Lengua Española: Sevilla, 7 al 10 octubre, 1992. Alcalá de Henares: Instituto Cervantes, pp. 721-740.

Pascual, E. (2015). "Aproximaciones a la caracterización prosódica de los subactos, la unidad discursiva mínima del sistema Val.Es.Co.”. En Cabedo, A. (ed.). Perspectivas actuales en el análisis fónico del habla. Tradición y avances en la fonética experimental. Valencia: Anejo 7 de Normas. Revista de Estudios Lingüisticos Hispánicos, pp. 137-150: https://ojs.uv.es/index.php/normas/pages/view/anejos (15/04/2016).

Pascual, E. (en preparación). Los elementos subestructurales en la conversación coloquial española: caracterización y propuesta de integración en un sistema de unidades.

Pérez, M. (2011). Aproximación a la didáctica de la sintaxis coloquial en bachillerato: el estudio de las construcciones incompletas. Valencia: Universitat de València.

Pérez, M. (2014). “Hacia una caracterización pragmaprosódica de las 'construcciones incompletas': Actos Suspendidos, Actos Truncados y reinicios”. Quaderns de Filologia: Estudis Lingüístics XIX: 223-243.

Pérez, M. (2015). "Las construcciones suspendidas o actos suspendidos: Ensayo de caracterización pragmaprosódica", Oralia, 18, pp. 213-234.

Pons (1998). Conexión y conectores: estudio de su relación en el registro informal de la lengua. Valencia: Universitat de València.

Pons, S. (2016). “Cómo dividir una conversación en actos y subactos”. En Bañón, A. M., Espejo, M. M., Herrero, B. y J. L. López (coords.). Oralidad y análisis del discurso: homenaje a Luis Cortés Rodríguez. Almería: Universidad de Almería, pp. 545-566.

Pose, F. (2011). Categorización de los cortes sintácticos en la entrevista semidirigida. Aproximación sociolingüística (estudio de los materiales del corpus PRESEEA-Granada). Granada: Universidad de Granada.

Quilis, A. (1988). Fonética Acústica de la lengua española. Madrid: Gredos.

Quilis, A: (1993). Tratado de fonética y fonología españolas. Madrid: Gredos.

Quilis, A., Cantarero, M. y M. Esgueva (1993). "El grupo fónico y el grupo de entonación en el español hablado", Revista de Filología Española, 73, 1/2, pp. 55-64.

Sacks, H., Schegloff, E. A., y G. Jefferson (1974). "A Simplest Systematics for the Organization of Turn-Taking for Conversation”, Language, 50, 4/1, pp. 696-635.

Schegloff, E. A. (1979). The Relevance of Repair to Syntax-for-Conversation, Syntax and Semantics, 12, pp. 261-286.

Schegloff, E. A., Jefferson, G. y H. Sacks (1977). "The Preference for Self-Correction in the Organization of Repair in Conversation", Language, 53, 2, pp. 361-382.

Shriberg, E. (1994). Preliminaries to a Theory of Speech Disfluencies. California: University of California at Berkeley.

Waltereit, R. (2005). "La polifonía prosódica: Copiar un patrón entonativo", Revista Internacional de Lingüistica Iberoamericana, 6, pp. 137-152. 